\title{
VIABILIDADE DE UTILIZAÇÃO DO MODELO SOYGRO PARA A REGIÃO DE LONDRINA
}

\section{LUIZ RENATO LAZINSKI}

Meteorologista

Orientador: Prof. Dr. ANTONIO ROBERTO PEREIRA

\begin{abstract}
Dissertação apresentada à Escola Superior de Agricultura "Luiz de Queiroz", da Universidade de são Paulo, Para obtenção do título de Mestre em Agronomia, área de concentração: Agrometeorologia.
\end{abstract}

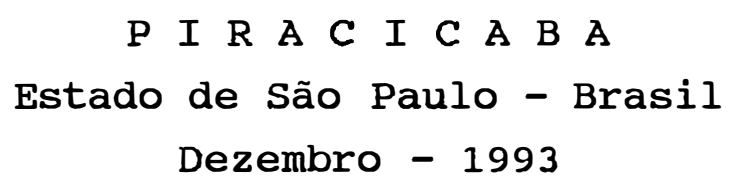


Ficha catadografica freparade peía Sefád de Livrus da

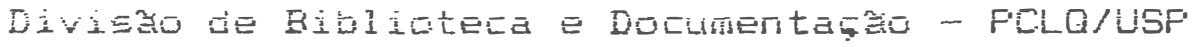

\footnotetext{
Lazinstíg Luiz Feñato LASiy Viabilidade da litiinagá do modelo Suygro para

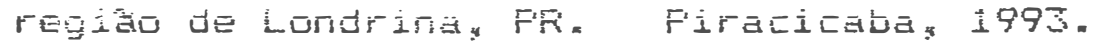

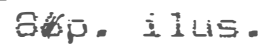
norte 2. Suja - Crescinento - Mudelo de simulagá B. Suja - Frudutividade - Farana (regiao norte)
} 


\section{VIABILIDADE DE UTILIZAÇÃO DO MODELO}

SOYGRO PARA A REGIÃO DE LONDRINA

LUIZ RENATO LAZINSKI

Aprovado em: 01.03 .94

Comissão julgadora:

Prof. Dr. Antonio Roberto Pereira

ESALQ/USP

Dr. Marcelo Bento Paes de Camargo

IAC

Prof. Dr. Valter Barbieri

ESALQ/USP

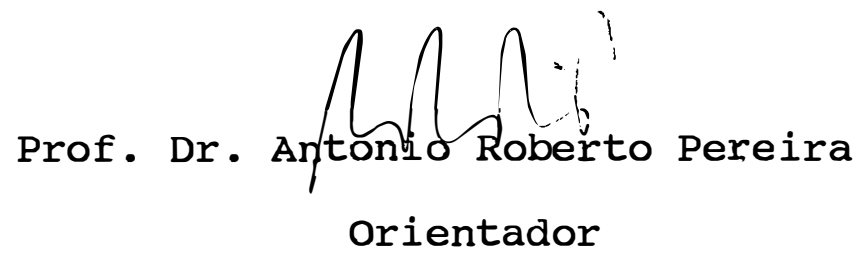


À minha esposa, Marilene, pelo apoio, incentivo e companheirismo

OFEREÇO

Aos meus pais, Renato e Rute, pelo estímulo e dedicação à minha formação 


\section{AGRADECIMENTOS}

- Ao Prof. Dr. Antonio Roberto Pereira pela orientação, apoio e confiança depositada em meu trabalho.

- Ao Instituto Nacional de Meteorologia, pela oportunidade oferecida para aprimorar meus conhecimentos.

- ̇̀ Escola Superior de Agricultura "Luiz de Queiroz", pela oportunidade de frequentar o curso de Pós-graduação.

- Ao Departamento de Física e Meteorologia da ESALQ/USP, e a todos os seus professores e funcionários pela colaboração e apoio concedido.

- Ao Dr. J.W. Jones da Universidade da Flórida (EUA), que gentilmente cedeu o modelo SOYGRO, e prontamente respondeu a todas as nossas perguntas.

- Aos colegas e amigos Maria Inês, Adriróseo, Sérgio, Henrique, Wagner, Tereza, Roberto, Beatriz e Jesus, pelo convívio e amizade. 
- À Coordenação de Aperfeiçoamento de Pessoal de Nível Superior (CAPES), pelo apoio financeiro.

- Ao Centro Nacional de Pesquisa de Soja (CNPSo-EMBRAPA), pelo fornecimento dos dados.

- A todos que de uma forma ou de outra, contribuiram para a realização deste trabalho. 
INDICE

Página

LISTA DE FIGURAS . . . . . . . . . . . . . . . viii

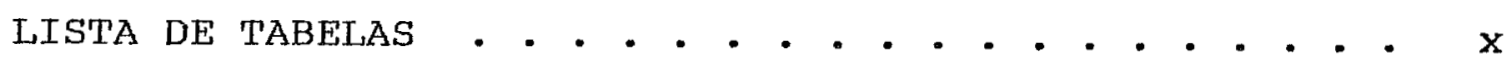
RESUMO •. . . . . . . . . . . . . . . . . . . . . xii

SUMMARY . • . . . . . . . . . . . . . . . . . . xiv

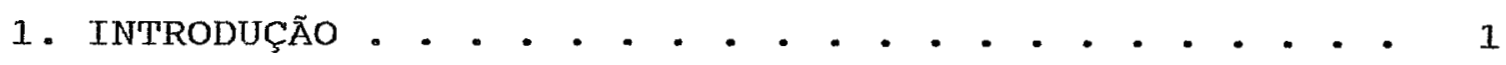

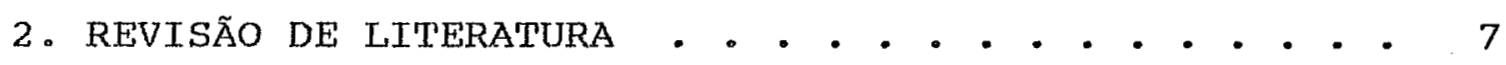

2.1 A cultura da soja . . . . . . . . . . . . . 7

2.2 Exigências climáticas . . . . . . . . . 10

2.2.1 Exigências térmicas . . . . . . . . 10

2.2.2 Exigências fotoperiódicas . . . . . . . 15

2.2.3 Exigências hídricas . . . . . . . . . 22

2.3 Modelos de estimativa de produtividade . . . . 28

3. MATERTAL E MÉTODOS • . . . . . . . . . . . . 36

3.1 Material utilizado. . . . . . . . . . . 36

3.1.1 Dados fenológicos e de produtividade . . 36

3.1.2 Dados meteorológicos . . . . . . . . 38

3.1.3 Solo . . . . . . . . . . . . . . . 39

3.2 Modelo utilizado . . . . . . . . . . . . 41

3.2.1 Parâmetros de entrada do modelo . . . . 43 
vii

3.2.2 Parâmetros de saída do modelo . . . . 47

3.3 Sensibilidade do modelo em relação aos parâmetros de entrada . . . . . . . . . . . . . 47 4

4. RESULtados E DISCUSSÕES • . . . . . . . . . . . . 49

4.1 Condições meteorológicas . . . . . . . . . 49

4.2 Estimativa das fases fenológicas e produtividade 56

4.3 Sensibilidade do modelo cọ relação aos parâmetros de entrada . . . . . . . . . . . . 63

5. CONCLUSÕES • • . . . . . . . . . . . . . . 72 .

REFERENCIAS BIBLIOGRÁFICAS . . . . . . . . . . 75 
viii

\section{LISTA DE FIGURAS}

Página

1 Períodos de desenvolvimento da soja . . . . . 9

2 Temperaturas médias mensais, normais no período $1961 / 1990$. . . . . . . . . . . . 51

3 temperaturas médias mensais, ano agricola 1976/77 • . . . . . . • . . . . 51

4 temperaturas médias mensais, ano agrícola $1977 / 78$. . . . . . . . . . . . 52

5 Temperaturas médias mensais, ano agrícola 1978/79 • . . . . . . . . . . 52

6 Totais mensais de precipitação para o ano agrícola $1976 / 77$. . . . . . . . . . . 53

7 Totais mensais de precipitação para o ano agrícola $1977 / 78$. . . . . . . . . . . 53

8 Totais mensais de precipitação para o ano

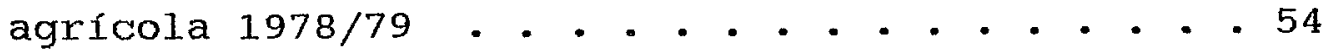

9 Insolação mensal para o ano agrícola 1976/77 • 54

10 Insolação mensal para o ano agrícola 1977/78 • • 55

11 Insolação mensal para o ano agrícola 1978/79 • 55

12 Produtividade simulada em função da variação profundidade de plantio . . . . . . 67 
13 Produtividade simulada em função da variação da densidade de plantio . . . . . . 67

14 Produtividade simulada em função da variação do albedo do solo . . . . . . . . . . . . . 68

15 Produtividade simulada em função da variação do coeficiente de evaporação do solo no estágio 1 . . . . . . . . . . . 68

16 produtividade simulada em função da variação da curva de escoamento . . . . . . . . . 69

17 Produtividade simulada em função da variação do coeficiente de drenagem . . . . . . . . 69

18 Produtividade simulada em função da variação do fator de moderação de distribuição das raizes 70 


\section{LISTA DE TABELAS}

Página

1 Produção dos principais países produtores, e produção mundial anual de soja, no período de 1989 a 1993 . . . . . . . . . . . . . 6

2 Produção e produtividade de soja para o Estado do Paraná e no Brasil, no período de 1983 a 1993 . . . . . . . . . . . . 6

3 Limites superior (capacidade de campo) e inferior (ponto de murcha permanente) de umidade do solo, utilizados no modelo. . . . . 40

4 Parâmetros de solo utilizados pelo modelo . . . 46

5 Dados de cada repetição e média, observados em campo para o ano agrícola 1976/77 . . . . . 57

6 Dados de cada repetição e média, observados em campo para o ano agrícola 1977/78 . • . . . 58

7 Dados de cada repetição e média, observados em campo para o ano agrícola 1978/79 . . . . . . 58

8 Florescimento e maturidade fisiológica, observado e simulado para os anos agrícolas $1976 / 77,1977 / 78$ e $1978 / 79$. . . . . . . . 61 
9 Produtividade observada e simulada para os anos agrícolas 1976/77, 1977/78 e 1978/79 • . 62

10 Número de grãos por $\mathrm{m}^{2}$ e massa de cada semente, observado e simulado para os anos agrícolas $1976 / 77,1977 / 78$ e 1978/79 • . . . . 62

11 Produtividade simulada em função da variação do limite superior de umidade do solo (capacidade de campo) . . . . . . . . . . 71

12 Produtividade simulada em função da variação do limite inferior de umidade do solo (ponto de murcha permanente) . . . . . . . 71 


\section{VIABII.IDADE DE UTIKIZAÇÃO DO MODELO}

SOYGRO PARA A REGIÃO DE LONDRINA

Autor: LUIZ RENATO LAZINSKI

Orientador: ANTONIO ROBERTO PEREIRA

RESUMO

As fases fenológicas e produtividade de soja para Região Londrina, norte do Estado do Paraná, foram estimadas utilizando um modelo de simulação de desenvolvimento e crescimento da soja denominado SOYGRO V5. 42 .

o modelo simula o desenvolvimento fenológico (duração dos es áaios vegetativos e reprodutivos) da cultura da soja (Glycile max (L.) Merrill) e balanço hidrico, em função dos elementos meteorológicos diários, do tipo de solo e da cultivar.

Os testes aplicados para avaliar a sensibilidade co modelo, mostraram que este é sensível à densidade de plíntio, às variáveis de solo, e principalmente, à variação de umidade do solo. Porém não mostrou 
sensibilidade em relação ao albedo e coeficiente de evaporação do solo no estágio 1.

o modelo requer dados meteorológicos diários de temperaturas máxima e minima, precipitação e radiação solar global. Dados de solo; albedo, coeficiente de evaporação do solo no estágio 1 , número da curva de escoamento (classificação americana), coeficiente de drenagem, espessura de cada camada de solo, fator de ponderação de distribuição de raízes em cada camada de solo, limites superior (capacidade de campo), inferior (ponto de murcha permanente) e umidade de saturação em cada camada de solo e quantidade inicial de umidade na data de semeadura $e$, dados genéticos da cultivar. Permite ainda entrar com manejo de irrigação e aplicação de fertilizantes.

As datas de florescimento e maturidade, fisiológica, número de sementes por $\mathrm{m}^{2}$, massa de cada semente e rendimento simulados pelo modelo, apresentaram resultados satisfatórios. Em geral, o modelo mostrou uma tendência em superestimar as produtividades, e aumentar os períodos semeadura-florescimento e semeadura-maturidade fisiológica. 
xiv

\title{
VIABILITY OF UTILIZATION OF THE SOYGRO MODEL FOR THE LONDRINA REGION
}

\author{
Author: Luiz Renato Lazinski \\ Adviser: Antonio Roberto Pereira
}

SUHMARY

The yield and development of a soybean crop grown in Londrina $\left(23^{\circ} 19^{\prime} \mathrm{S}\right.$ latitude, $51^{\circ} 09^{\prime} \mathrm{W}$ Iongitude, altitude $566,0 \mathrm{~m})$, in the Northern Region of the Parana state, was estimated using the simulation model sOYGRO V5.42.

The model simulates the crop development (duration of the vegetative and reprodutive periods) for a given cultivar, and the water balance, as a function of the daily weather data, for specific soil. The daily weather inputs the maximum and minimum temperatures, rainfall and solar radiation. Soil characteristics includes, albedo, stage 1 evaporaton, whole-profile drainage rate coefficient, Runoff curve number, weighting factor for root ditribution, layer thickness, lower limit of plant-extractable water (permanent witting point), drained upper limit (field capacity), water content at saturation and water content at the sowing date. 
The test applied to evaluate the sensitivity of the model, idicates that the model is sensitive to population density, to soil variables, mainly, to change of the soil moisture. However, the tests indicated that the model is not sensitive to changes in the soil albedo and stage 1 evaporation.

The model outputs the dates of the flowering and physiological maturity, seed number per $\mathrm{m}^{2}$, mass per seed ( $g$ ) and seed yield simulated. In general, the model results indicate tendency in overestimation of the crop yield and increased the sowing-flowering and sowing-physiological maturity periods. 


\section{INTRODUÇÃO}

No Brasil, até meados dos anos 60 , a soja não tinha importância econômica dentre as principais culturas como a cána-de-açúcar, algodão, milho, arroz, café, laranja e feijão. No entanto, a partir do final da década de 60, a produção de soja vem crescendo significativamente.

Devido a rápida expansão da soja pelo território nacional, o Brasil tornou-se o segundo maior produtor e exportador de soja do mundo. Tem potencial para se tornar o maior produtor, uma vez que a soja pode ser produzida em muitas áreas, potencialmente favoráveis para a expansão desta cultura. A tabela 1 mostra a produção anual de soja dos principais países produtores e a produção mundial anual, no período de 1989 a 1993.

A soja atualmente se destaca, como a principal fonte para a produção de óleo vegetal no mundo. É um dos produtos agricolas que tem uma participação marcante na economia do pars, contribuindo significativamente para o 
Produto Interno Bruto (PIB). Segundo ROESSING \& GUEDES (1993), em 1990 o setor agrícola contribuiu com 9,5\% do PIB nacional, sendo que somente a soja representou 1,05\% do PIB, e 11,06 \%o PIB agrícola.

o Estado do Paraná possui um dos melhores índices de produtividade, e é atualmente o maior produtor de soja do país. A importância desta planta, deve-se ao fato de ser muito utilizada na rotação de culturas, principalmente com o trigo, outra cultura bastante cultivada no Estado. A tabela 2 mostra a produção e produtividade da soja para o Brasil e para o Estado do Paraná, no período de 1983 a 1993.

A produção de grãos vem crescendo bastante no Brasil, porém para aumentar a produção, não é suficiente somente a ampliação das fronteiras agrícolas, é necessário melhorar a produtividade no setor rural, utilizando-se de novas técnicas de plantio, seleção de novas cultivares e, principalmente, utilização mais racional dos recursos naturais e das condições climáticas.

Nos últimos anos, uma série de fatores tem contribuido para melhorar a produtividade agrícola, como o uso de modelos de simulação dos sistemas biológicos. o desenvolvimento destes modelos foi possível, devido ao grande avanço na área de simulação matemática e a popularização dos computadores, capazes de executar grande quantidade de 
operações aritméticas e lógicas em tempo reduzido (PEREIRA, 1987) .

Os modelos agrometeorológicos e a interpretação de dados climáticos, relacionados com o desenvolvimento, crescimento e produtividade das culturas, fornecem informações que permitem ao setor agrícola tomar importantes decisões, tais como, melhor planejamento do uso do solo, adaptação de culturas, monitoramento e previsão de safras, controle de pragas e doenças, estratégia de pesquisa e planejamento.

Apesar dos grandes avanços na área de informática, no desenvolvimento de modelos dinâmicos e mecanismos mais sofisticados de simulação de crescimento e desenvolvimento das plantas, os modelos tradicionais empírico-estatisticos continuam sendo bastante utilizados (ROBERTSON, 1983), pelo fato de serem feitos para operar com um minimo de dados. Por esta razão são aplicáveis, geralmente, para as condições locais onde foram desenvolvidos.

PEREIRA (1987) cita os modelos matemáticos como excelentes mecanismos de previsão, e que um modelo deve ser suficientemente simples para permitir sua manipulação e entendimento, e suficientemente complexo para permitir extrapolações e conclusões. 
o presente trabalho utiliza o modelo de simulação de crescimento e desenvolvimento da soja SOYGRO V5.42, desenvolvido por um grupo de pesquisadores da Universidade da Florida (EUA) (JONES et alli, 1989). O SOYGRO é um modelo dinâmico que simula diariamente 0 crescimento, desenvolvimento e produtividade da soja. Contém equações que descrevem as relações de desenvolvimento, fotossintese, respiração, transpiração, consumo de água, crescimento das folhas, caules, vagens e grãos com o fotoperíodo, temperatura, insolação e disponibilidade de água. Calcula também o balanço de água no solo, associado ao crescimento da planta. Por ser um modelo bastante sofisticado, requer como dados de entrada informações genéticas da cultivar, dados meteorológicos diários e informações sobre o solo e tratos culturais.

o presente trabalho tem por objetivos;

- Testar o modelo SOYGRo V5.42 para as condições de solo e clima na Região de Londrina, Norte do Estado do Paraná.

- Testar a sensibilidade do modelo em relação aos parâmetros de entrada, como profundidade de semeadura e densidade de plantio, e de solo: albedo, coeficiente de evaporação do solo no estágio 1 , número da curva de 
escoamento, coeficiente de drenagem e fator de moderação de distribuição de raízes.

- Verificar a habilidade do modelo em estimar a produtividade. 
Tabela 1 - Produção de soja dos principais paises produtores e produção mundial (em 1.000 ton)

\begin{tabular}{cccccc}
\hline \multicolumn{1}{c}{ ANO } & EUA & BRASII & ARGENT. & CHINA & MUNDO \\
\hline 1989 & 52.534 & 24.087 & 10.750 & 10.230 & 107.111 \\
1990 & 52.416 & 19.850 & 11.500 & 11.000 & 105.576 \\
1991 & 54.065 & 15.522 & 11.200 & 9.710 & 103.777 \\
1992 & 59.779 & 19.175 & 11.500 & 9.700 & 112.794 \\
$1993^{1}$ & 56.427 & 21.173 & 12.500 & 11.000 & 115.200 \\
\hline \hline
\end{tabular}

1 Dados preliminares

Fonte: Roesing \& Guedes (1993)

Tabela 2 - Produção (em 1.000 t) e rendimento médio (kg/ha) de soja, no Paraná e no Brasil.

\begin{tabular}{ccccc}
\hline \multirow{2}{*}{$\begin{array}{c}\text { SAFRA } \\
\text { ANO }\end{array}$} & \multicolumn{2}{c}{ PARANÁ } & \multicolumn{2}{c}{ BRASIL } \\
\cline { 2 - 5 } $1983 / 84$ & 4.121 & 1.892 & 15.541 & 1.650 \\
$1984 / 85$ & 4.413 & 2.009 & 18.278 & 1.800 \\
$1985 / 86$ & 2.600 & 1.490 & 13.400 & 1.405 \\
$1986 / 87$ & 3.810 & 2.218 & 16.698 & 1.857 \\
$1987 / 88$ & 4.771 & 2.247 & 18.053 & 1.702 \\
$1988 / 89$ & 5.031 & 2.096 & 24.087 & 1.971 \\
$1989 / 90$ & 4.650 & 2.050 & 19.850 & 1.731 \\
$1990 / 91$ & 3.531 & 1.790 & 15.522 & 1.620 \\
$1991 / 92$ & 3.417 & 1.905 & 19.175 & 2.012 \\
$1992 / 93^{1}$ & 4.200 & 2.100 & 21.173 & 2.014 \\
\hline \hline
\end{tabular}

1 Dados preliminares

Fonte: Roesing \& Guedes (1993) 


\section{REVISÃO DE LITERATURA}

\subsection{A cultura da soja}

A soja é uma cultura bastante antiga, e a primeira referência sobre esta cultura é atribuida a shengNung, onde descreve as plantas da China em sua obra médica, escrita à 2.830 ac. Pesquisas indicam que a soja é cultivada a mais de cinco mil anos na Ásia. Apesar de ser uma cultura antiga, sua expansão à nível mundial ocorreu somente no começo deste século, sendo um dos produtos agrícolas que mais tem se destacado e expandido como cultivo para produção de grãos. Hoje é a mais importante oleaginosa cultivada extensivamente, e produz mais proteina por hectare que qualquer outra planta ou lavoura. É considerada a mais rica leguminosa. Sua composição química mostra um alto valor nutritivo, principalmente pelo alto teor de proteína e os aminoácidos essenciais que ela contém (BONETTI, 1977; VERNETTI, 1975) . 
No Brasil, a referência mais antiga sobre a soja, foi relatada no Estado da Bahia no ano de 1882. Em 1891, foi cultivada pela primeira vez em são Paulo, expandindo-se posteriormente pelos Estados do sul do país (SEDIYAMA et al1i, 1985)。

Atualmente é um dos produtos agrícolas de maior importância na economia brasileira, sendo que grande parte da nossa produção destina-se ao mercado externo. Nos últimos anos, o Brasil tornou-se o segundo maior produtor e o segundo maior exportador mundial de soja.

Inicialmente a soja foi utilizada na alimentação animal, mas seu uso na alimentação humana tem crescido rapidamente. Na agricultura, é utilizada principalmente como adubação verde e conš̉ervação do solo (OSMAR, 1988).

o período total de crescimento da soja, bem como suas fases estão ilustradas na figura 1. 


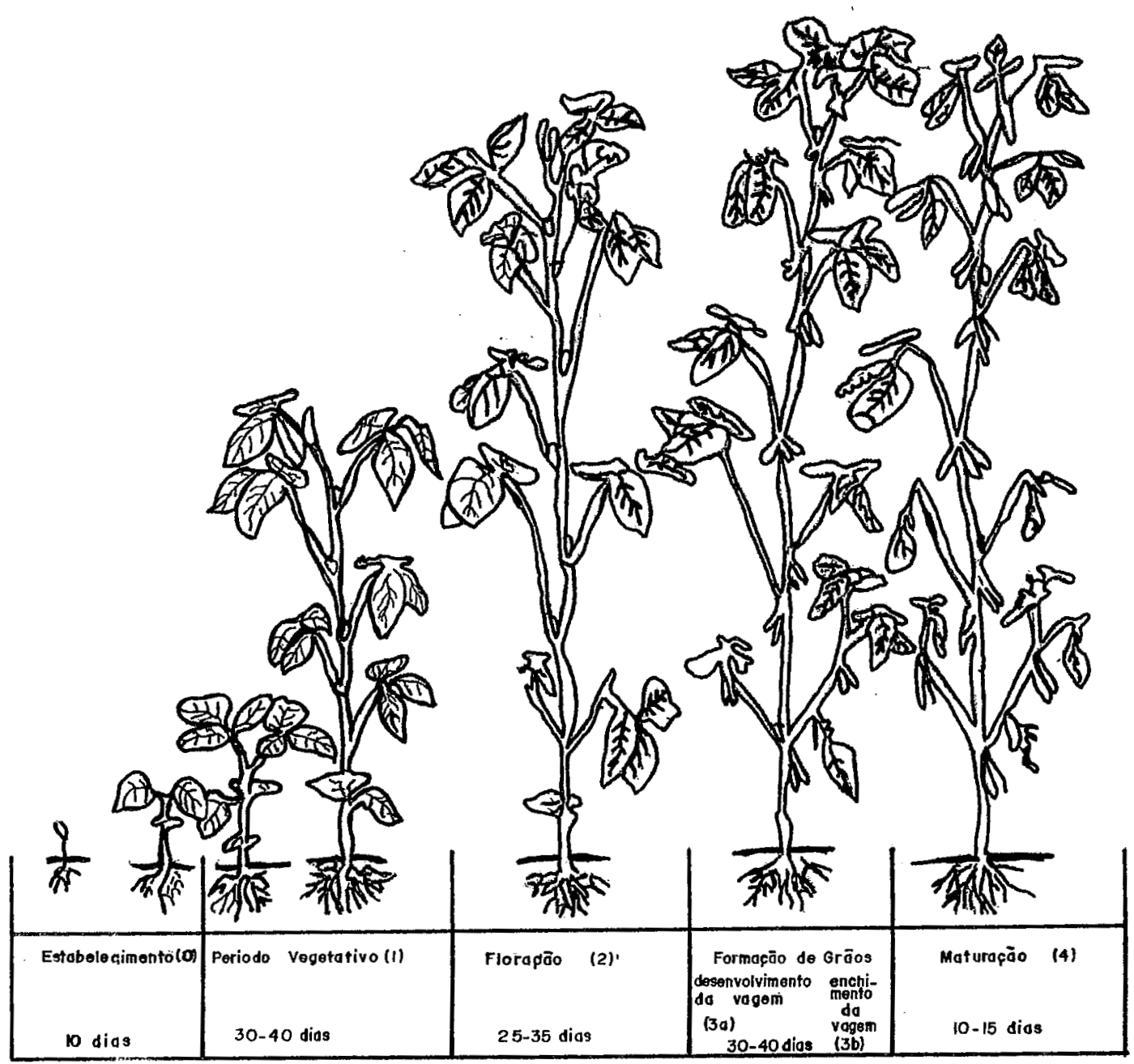

Figura 1 - Períodos de desenvolvimento da soja (Fonte: DOORENBOS \& KASSAM, 1979) 


\title{
2.2 Exigências climáticas
}

\begin{abstract}
A soja é uma leguminosa originária de clima temperado, no entanto tem-se adaptado a uma ampla faixa de condições climáticas. Segundo SEDIYAMA et alli (1985), pesquisas recentes indicam grandes possibilidades de expansão desta cultura nas regiões tropicais.

As plantas respondem de maneira diferente frente aos fatores ambientais, nas diversas fases de desenvolvimento da cultura. PASCALE et alli (1963) destacam a temperatura, o fotoperíodo e a umidade do solo, como os elemetos climáticos que influenciam no desenvolvimento da soja.
\end{abstract}

\subsubsection{Exigências térmicas}

Em muitas culturas a duração do ciclo vegetativo pode ser descrito em termos de exigências bioclimáticas, por um só elemento, a temperatura. Considerada como soma de temperaturas, unidades térmicas, unidades calóricas ou graus dias, denominações que significam a quantidade de energia que as plantas necessitam para completar o ciclo, desde a emergência até a colheita. Outras como a soja, apresentam um efeito combinado da temperatura com o comprimento do dia, e a reação das cultivares em relação ao ambiemte levou a 
classificá-las em 10 grupos de maturação, que vai das variedades mais precoces às muito tardias, segundo suas exigências térmicas e fotoperiódicas, para que possam completar o ciclo (PASCALE \& ESCALES, 1971).

A emergência da plântula depende da profundidade de plantio do cultivar, e da temperatura do solo. A temperatura do solo por sua vez, determina o número de dias necessários para ocorrer a emergência. Para SCHNEIDER et alli (1988), a velocidade de emergência das plantas torna-se praticamente nula, quando na profundidade de semeadura, a temperatura do solo atinge $10^{\circ} \mathrm{C}$, aumentando progressivamente com o acréscimo da temperatura média do solo até atingir $29^{\circ} \mathrm{C}$ (temperatura considerada ótima). Por outro lado, temperaturas médias do solo superiores à $30^{\circ} \mathrm{C}$, diminuem a velocidade de emergência da soja. Temperatura do solo adequada na época de plantio, é de fundamental importância para que a soja tenha emergência uniforme e rápida (EMBRAPA, 1992).

Trabalhando com soja em ambiente controlado, BROWN (1960) mostrou que a relação entre o desenvolvimento e a temperatura tem um aspecto parabólico, e que a temperatura base ocorreu próximo à $10^{\circ} \mathrm{C}$ e atingiu um ótimo próximo à $30^{\circ} \mathrm{C}$. Temperatura base, é a minima necessária para que os processos fisiológicos de crescimento e desenvolvimento se iniciem. 
Vários pesquisadores tem mostrado que o crescimento da planta é muito lento com temperaturas entre $10^{\circ} \mathrm{C}$ e $15^{\circ} \mathrm{C}$ (MAJOR, 1980; EMBRAPA, 1992; SCHNEIDER et al1i, 1988). o aumento gradual da temperatura do ar, segundo SCHNEIDER et alli (1988), determina um aumento na taxa de crescimento da soja até atingir a temperatura de $30^{\circ} \mathrm{C}$, onde esta taxa é máxima. Para temperaturas acima deste valor, ocorre uma redução progressiva da taxa de crescimento da soja.

Analisando o comportamento de diferentes variedades de soja na Argentina, PASCALE et al1i (1963) verificaram que em condições normais, a semente necessita de uma acumulação térmica de $180^{\circ} \mathrm{C}$ a $200^{\circ} \mathrm{C}$, para atingir a emergência. No sub-período floração-frutificação, as variedades precoces tem uma duração menor, à medida que se atrasa o plantio. Já o sub-período frutificação-maturação, é uma fase da cultura influênciada exclusivamente pela temperatura. o ciclo vegetativo total da cultura (emergênciamaturação), com excessão das variedades precoces, diminui à medida que que se atrasa o plantio, e as somas térmicas requeridas para cumprir o ciclo, são assim, cada vez menores. Para a floração da soja, SCHNEIDER et alli (1988) sugerem que a temperatura média do ar ótima está entre $24^{\circ} \mathrm{C}$ e $25^{\circ} \mathrm{C}$. Sob temperaturas médias do ar inferiores à $17^{\circ} \mathrm{C}$, 
inibem seriamente a indução floral, e superiores à $38^{\circ} \mathrm{C}$ resultam em grande abortamento de flores e vagens.

As diferenças de data de floração entre anos, apresentadas por uma mesma cultivar semeada numa mesma época, são devidas às variações de temperatura. Assim, a floração precoce é devido, principalmente, à ocorrência de temperaturas mais altas, podendo acarretar uma diminuição na altura da planta. Já a maturação pode ser acelerada por ocorrência de altas temperaturas. Quando vem associadas a períodos de alta umidade, as altas temperaturas contribuem para diminuir a qualidade das sementes e, quando associadas à condições de baixa umidade, predispõe as sementes à danos mecânicos durante a colheita. Temperaturas baixas na fase da colheita, associadas a período chuvoso ou de alta umidade, podem provocar um atrazo na data da colheita, bem como ocorrência indesejável de retenção foliar (EMBRAPA, 1992).

Estudando a influência de fatores ambientais, que afetam o florescimento e o desenvolvimento das plantas, MAJOR (1980) verificou que a temperatura influencia na taxa de desenvolvimento e no número de flores que produzem sementes maduras.

Na interação entre acumulação térmica e fotoperíodo, CAMARGO (1984) constatou que a temperatura influencia mais significativamente nas cultivares menos sensiveis ao fotoperíodo (ciclo curto), e que o elemento 
climático que mais influenciou na duração do ciclo, entre as localidades de campinas (SP) e Ribeirão Preto (SP), foi a temperatura. Ribeirão Preto (SP), por apresentar temperaturas médias superiores a Campinas (SP), provocou ciclos mais curtos, em plantios de mesma época, devido ao acúmulo mais rápido de unidades térmicas, mostrando a importância da temperatura, principalmente na cultivar Paraná (ciclo curto), menos afetado pelo fotoperíodo.

MAYERS et alli (1991), trabalhando com 8 genótipos de soja semeadas em intervalos semanais em duas localidades, observaram que o tempo para os genótipos atingirem o florescimento, foi maior no ano onde a temperatura média foi menor. Para os genótipos precoces foi marcante a influência da temperatura para o florescimento, enquanto que o fotoperíodo praticamente não influênciou. Já para os genótipos tardios, tanto a temperatura quanto o fotoperíodo influenciaram no florescimento. Utilizando um modelo Iinear para testar as relações entre os genótipos, fotoperíodo e temperatura, o florescimento foi negativamente associado com a temperatura máxima média e fotoperíodo médio, e positivamente associado com a temperatura mínima média, mostrando a importância da temperatura minima nesta fase. Também observaram que os genótipos, apesar de suas origens diferentes, atingem seu desenvolvimento ótimo com temperaturas entorno de $30^{\circ} \mathrm{C}$. Em contraste com as respostas 
dos genótipos na fase pré-florescimento, o efeito da temperatura mínima na fase reprodutiva teve menor importância que as temperaturas mảxinas.

SEDDIGH \& JOLLIFF (1984) estudando o efeito da temperatura noturna na cultura da soja, para variedades precoces (grupo de maturidade 0 ), concluiram que altas temperaturas noturnas diminuem a fase vegetativa, e antecipam - desenvolvimento reprodutivo e maturidade fisiológica, aumentando a produtividade de grãos. Embora as altas temperaturas noturnas, aumentem a taxa de crescimento da cultura durante a fase vegetativa, matéria seca final e o peso da vagem, o índice de área foliar diminui com o aumento da temperatura noturna.

\subsubsection{Exigências fotoperiódicas}

A soja é considerada uma planta de dias curtos, sua reação à duração do dia é diferente segundo a variedade e a temperatura. Pesquisadores tem mostrado que os dias curtos estimulam a floração, especialmente no caso das variedades de ciclo tardio (DOORENBOS \& KASSAM, 1979). 
- fotoperiodismo como controlador do florescimento, foi descoberto por Garner \& Allard (1920) ${ }^{1}$ citado por SEDIYAMA et alli (1985), quando observaram que o comprimento do dia afeta os periodos vegetativos e de frutificação em muitas plantas, inclusive a soja.

Historicamente, o fotoperíodo como regulador do florescimento da soja, tem sido um dos fatores mais pesquisados. Para SEDIYAMA et alli (1985), é o fator de maior importância na determinação da proporção relativa entre os períodos vegetativos e reprodutivos, influenciando também, no periodo de florescimento até a formação da vagem, e daí até a maturação. Na soja, como planta tipicamente de dias curtos, seu florescimento ocorre mais cedo sob fotoperíodos menores. o atraso no florescimento ocorre com fotoperíodos longos. o fotoperíodo critico varia de acordo com a temperatura e é maior sob temperaturas altas. o atraso no florescimento não aumenta somente como uma função do aumento do fotoperíodo, mas também como uma função da diminuição da temperatura. o fotoperiodo crítico, definido por MAJOR (1980), é o máximo comprimento do dia, no qual uma planta de dias curtos atinge o florescimento, e o mínimo comprimento do dia no qual uma planta de dias longos atinge o florescimento. 0

${ }^{1}$ GARNER, W.W \& ALLARD,H.A. Effect of relative lenght of day and nigth and other factors of the environment on growth and reproduction in plants. Jour Agric. Res., 18: 553-606, 1920. 
fotoperiodo critico pode ser diferente entre cultivares de uma mesma espécie, e frequentemente está associado à latitude de adaptação. Cultivares de baixas latitudes, tem fotoperíodo crítico menor que cultivares de altas latitudes.

Para CAMARGo (1984), a duração do ciclo da soja sofre influência marcante do fotoperíodo e da época de plantio. Trabalhando com cultivares de ciclo curto (Paraná), semi-precoce (Viçoja) e ciclo longo (UFV-1), mostrou que para cultjvares de ciclo curto a interferência da época de plantio sobre o ciclo total é bem menor. A redução do ciclo total (plantio/maturação), em função do atraso da época de plantio, principalmente nos cultivares de ciclo médio a longo, é devida a maior sensibilidade dessas cultivares à redução do comprimento do dia, que as variedades precoces. Concluindo, que o fotoperíodo, que faz com que a planta complete seu ciclo com menor acumulação térmica a medida que atrasa o plantio, é um dos fatores determinante no somatório térmico. Cada variedade exige um mínimo critico de ausência de luz (periodo de escuro) para que seja induzida ao florescimento. Desta maneira poderá permanecer em seu período vegetativo quase que indefinidamente, se os dias forem bastante longos, ou poderá florescer num periodo inferior a um mes, se os dias forem suficientemente curtos (SEDYIAMA et alli, 1985). Porém, existem variedades de soja que apresentam um período de juvenilidade bastante longo, independente do 
fotoperíodo. Alguns genótipos de soja estudados por HADLEY et alli (1984), aparentemente apresentaram um período máximo para o florescimento, que nunca é excedido, sob qualquer regime fototérmico.

Em estudos efetuados para determinar os efeitos do comprimento do dia e da temperatura no desenvolvimento de cultivares de soja, MAJOR et alli (1975) observaram que a maior diferença entre as cultivares foi com relação à sensibilidade ao comprimento do dia no florescimento, sendo que as cultivares tardias foram mais sensiveis que as precoces.

Para descrever a resposta da soja ao comprimento do dia, estabeleceu-se para as condições dos EUA, dez grupos de maturação numerados de 00, O, I a VIII. As variedades dos grupos 00,0 e I são as mais precoces em maturação e podem tolerar os dias longos das altas latitudes, já as variedades dos grupos VII e VIII são tardias e se desenvolvem em regiões de dias curtos das baixas latitudes.

Hartwig $(1973)^{2}$, citado por CAMARGO (1984), afirma que a classificação em grupos de maturação não tem validade quando não se menciona a latitude da região.

${ }^{2}$ HARTWIG, E.E. Varietal development. In: GALDWELL,B.E. Ed. soybeans: Improvement production and uses. American Soc. Agron., Madison, p. 187-210, 1973. 
A duração do sub-período emergênciaflorescimento, depende da época de plantio. o número de dias para completar o sub-período, diminui com o atraso na época de semeaduraI. A aceleração da floração com o atraso no plantio foi proporcionalmente maior no grupo de maturação maior (PASCALE \& ESCALES, 1971).

CAMARGO (1984) mostrou que o ciclo total (plantio/maturação) em dias, da variedade Paraná, foi maior na localidade de Passo Fundo (RS), que para localidades de menor latitude como Londrina (PR) e Ribeirão Preto (SP), sugerindo qua a variedade Paraná, classificada como ciclo curto para as coordenadas geográficas do Estado de são Paulo, pode ser enquadrada como ciclo médio no Rio Grande do Sul. Isto mostra que em latitudes maiores, o fotoperiodo crítico ocorre mais tarde, havendo consequente aumento no ciclo da planta. A duração do ciclo total (plantio/maturação) da soja é sensivelmente reduzida numa localidade à medida que se atrasa o plantio. A causa principal desta variação é a mesma ocasionada pela latitude, ou seja o fotoperiodo.

As variedades precoces atingem a floração em um número de dias muito similar, independente da data de semeadura, mostrando que estas variedades possuem uma indiferença fotoperiódica, enquanto que as variedades tardias exigem um fotoperíodo minimo para florescer (PASCALE et alli, 1963). 
A resposta fotoperiódica é o fator determinante para a latitude onde a soja será cultivada. Cultivares de soja adaptadas às regiões temperadas da América do Norte, segundo GREGAN \& HARTWIG (1984), são frequentemente improdutivas quando crescem sob condições de dias curtos, porque $\circ$ florescimento e consequentemente o crescimento reprodutivo são iniciados antes de ocorrer um adequado crescimento vegetativo. o principal fator que determina o tempo para o florescimento da soja é o comprimento do dia, consequentemente a resposta fotoperiódica, é o melhor critério para determinar a latitude de adaptação dos genótipos de soja.

THOMAS \& RAPPER (1983), trabalhando com uma variedade de soja tardia, sob condições controladas de fotoperíodo e temperatura, observaram que a soja, como planta de dias curtos, acelera seu desenvolvimento reprodutivo à medida que diminui o comprimento do dia. O intervalo de tempo entre a emergência e o florescimento é altamente influenciado pela temperatura, mantendo-se o fotoperiodo constante, este intervalo de tempo aumenta, à medida que a temperatura diminui.

A rápida expansão da soja no Brasil, vinda de latitudes maiores e avançando em direção ao Equador, tem levado a uma melhor adequação das cultivares aos novos ambientes, através da pesquisa. FINARDI \& BERGAMASCHI (1980) 
analizaram o comportamento de cultivares de soja de diferentes grupos de maturação em diferentes épocas de semeaduras no Rio Grande do Sul. O atraso na época de semadura ocasionou redução na duração do ciclo total e dos periodos de pré-florescimento, florescimento e pósflorescimento. As cultivares tardias apresentaram maior redução no ciclo total e dos períodos de pré-florescimento e florescimento, enquanto que as cultivares precoces apresentaram comportamento inverso, com maior redução no período pós-florescimento.

o fotoperíodo também exerce influência marcante na taxa de enchimento de grãos. Para THOMAS \& RAPPER (1976), - controle básico para a intensidade de enchimento de grãos, e a diminuição do intervalo de tempo entre o início da formação de grão e a maturidade fisiológica, é devido ao fotoperíodo.

Quanto ao efeito da temperatura na duração do ciclo da cultura, SCHNEIDER et alli (1988), afirmam que este efeito é maior nas cultivares menos sensiveis ao fotoperiodo, ou na ausência de uma forte resposta fotoperiódica. Assim, as cultivares precoces, necessitam mais calor e são menos sensiveis ao fotoperiodo que as tardias, enquanto que nas variedades tardias o fotoperíodo exerce efeito relativo mais acentuado. 


\subsubsection{Exigências hídricas}

Um dos principais responsáveis pelas variações de rendimento de grãos de soja, é a disponibilidade hidrica do solo, que afeta todos os processos fisiológicos da planta. A água constitui aproximadamente $90 \%$ do peso da planta e tem papel importante na sua regulação térmica, agindo tanto no resfriamento como na manutenção e distribuição de calor (EMBRAPA, 1992).

A água do solo utilizada pelas plantas, corresponde ao intervalo compreendido entre a "Capacidade de Campo" (CC) e o "Ponto de Murcha Permanente" (PMP). Para SEGOVIA \& ANDRADE (1982), o desenvolvimento da planta em função da umidade do solo disponível, atinge seu ótimo crescimento quando esta umidade se encontra entre 70 à $80 \%$ da Capacidade de campo. A necessidade de água de uma planta depende fundamentalmente da fase de desenvolvimento em que se encontra.

Solos profundos, de textura fina e alto conteúdo de matéria orgânica, segundo BONETTI (1979), tem elevada capacidade de retenção de umidade, em contraste com solos arenosos.

A influência do déficit hídrico sobre certos estágios da cultura, segundo BRUNINI et alli (1982) tem importância quantitativa diferente sobre o desenvolvimento da 
cultura. o efeito deste déficit não é tão drástico no estágio final da cultura (fase de maturação), como no período de florescimento e/ou formação de grãos, onde afeta sensivelmente a produção.

A soja requer um mínimo de $50 \%$ do seu peso em conteúdo de áqua antes de iniciar o processo de germinação, enquanto que a semente de milho necessita absorver somente $30 \%$ do seu peso antes de iniciar o processo de germinação (BONETTI,1979; SEDYIAMA et alii, 1985).

A deficiência de umidade no solo durante 0 subperíodo semeadura-emergência, segundo SCHNEIDER et alli (1988), resulta em emergência irregular e baixa população de plantas. Por outro lado, o excesso de umidade neste mesmo subperíodo, também é prejudicial. Num solo saturado ou próximo da saturação, a difusão do oxigênio é deficiente, prejudicando o processo respiratório da semente.

Analisando as exigências bioclimáticas da soja, PASCALLE et alli (1963) verificaram que a umidade, junto com a temperatura, são os parâmetros climáticos mais importantes no desenvolvimento de uma cultura. A germinação é um período crítico, na falta de água no solo, após a germinação, a soja suporta bem a falta de água durante a fase vegetativa, até a floração. o excesso de água no solo e umidade elevada na atmosfera, associado a um regime tếrmico favorável, dificulta - conclusão do ciclo do cultivo. A umidade representa um 
fator bioclimático de incidência direta no crescimento e consequentemente no rendimento.

o déficit ou excesso de água, durante o periodo vegetativo, retardam o crescimento. os períodos de desenvolvimento mais sensiveis ao déficit hídrico, são germinação-emergência e floração-enchimento de grãos (desenvolvimento das vagens), quando o déficit hidrico pode ocasionar forte queda de flores e vagens (DOORENBOS \& KASSAM, 1979) .

A necessidade de água da cultura da soja vai aumentando com o desenvolvimento da planta, atingindo 0 máximo durante a floração-enchimento de grãos ( 7 a $8 \mathrm{~mm} / \mathrm{dia}$ ) (EMBRAPA ,1992), decrescendo após este período. Para a obtenção de un máximo rendimento, a necessidade de água da cultura da soja durante todo seu ciclo, varia de 450 a 800 mm, dependendo das condições climáticas, do manejo da cultura e da duração do seu ciclo.

Várias pesquisas tem sido feitas para avaliar o efeito do déficit hídrico no desenvolvimento e crescimento da soja, por ser um dos principais fatores limitantes da produtividade. Para determinar a resposta da soja aos efeitos de déficit hídrico, BROWN et alli (1985), verificaram que a ocorrência deste déficit, na cultura de soja, tem sido um dos principais fatores da diminuição de produtividade. A soja é mais sensivel ao déficit hídrico durante a fase reprodutiva, 
que durante a fase vegetativa. o período crítico da soja, é a fase de enchimento de grão (enchimento da vagem), quando a planta necessita de umidade adequada para alcançar a máxima produtividade. Déficit hídrico nesta fase reduz drasticamente a produção de grãos. Os resultados mostram claramente que o déficit hídrico também diminui o tamanho e o número de grãos, causando a redução da produtividade.

$\mathrm{Na}$ fase de crescimento vegetativo, a deficiência de umidade acarreta reduções nos processos metabólicos e fisiológico das plantas, com reflexos na produtividade final da cultura. BONETTI (1979) observou que os maiores decréscimos na produtividade, devido ao déficit hídrico, ocorreu no sub-periodo de florescimento, na formação e desenvolvimento de vagens e no sub-período de enchimento de grãos. o decréscimo da produtividade decorrente de periodos de estiagem durante o florescimento, é devido à grande incidência de abortamento de flores, e permitiu as seguintes conclusões: a) variedades que possuem sementes de tamanho pequeno, emergem mais rápido e necessitam menor quantidade de água para germinação; b) disponibilidade de água após o subperíodo do florescimento é mais importante para o rendimento da soja do que o espaçamento ou densidade de semeadura; c) a soja tem um período crítico causado por déficit hidrico que coincide com o estágio de enchimento de grãos; d) diferentes variedades de soja se comportam diferentemente às condiçóes 
de umidade no solo; e e) tanto o excesso quanto o déficit de água podem reduzir drasticamente a produtividade da soja.

Avaliando os efeitos de umidade no desenvolvimento da soja, BROWN \& CHAPMAN (1960) mostraram que - déficit hídrico apressou o desenvolvimento da soja durante - florescimento e a maturidade, porém retardou o período pósflorescimento.

A maioria dos pesquisadores referem-se a períodos criticos da vida da planta em relação à falta de umidade. Existem poucos trabalhos relacionados com exceso de água na cultura da soja. costa (1973) testou a capacidade da soja resistir a diferentes periodos de inundação durante seu ciclo de desenvolvimento, determinando os efeitos de umidade no solo durante a fase de crescimento da planta, e verificou que as sementes de soja mesmo permanecendo cobertas de água durante 10 dias após terem sido semeadas, ainda conseguiram germinar, e mesmo pemanecendo inundadas por quatro meses, as plantas permaneceram vivas, completaram o ciclo e produziram grãos. BARNI \& COSTA (1976), também trabalharam com cultivares de soja em solos saturados, e concluiram que a inundação do solo durante $\circ$ sub-periodo emergênciaflorescimento limitou acentuadamente o crescimento das plantas, reduzindo o ciclo vegetativo com período de inundação de 30 dias durante o estádio de florescimento. Periodos de inundação de 15 dias de duração, do florescimento 
em diante, aumentaram o ciclo da cultura. E que após seu completo estabelecimento, a soja pode sofrer períodos de inundação do solo de até 15 dias sem perecer.

Trabalhando com o modelo SOYGRO, para avaliar os efeitos de mudanças climáticas na produtividade da soja, CURRY et alli (1990), verificaram que o excesso de precipitação pode diminuir a produtividade da soja, particularmente se ocorrer durante o estabelecimento da planta e na colheita.

\subsection{Modelos de estimativa de produtividade}

A interpretação do tempo em relação ao desenvolvimento das culturas, crescimento e produtividade, é uma das principais propostas dos modelos numéricos agrometeorológicos. Interpretações numéricas das condições do tempo em relação ao desenvolvimento das culturas, tem muitos usos na agricultura. Alguns destes usos incluem planejamento do uso do solo, zoneamento agricola, tomada de decisão, estudos morfológicos e fisiológicos das culturas, avaliação de impactos climáticos, manejo de irrigação, previsão de desenvolvimento, maturidade e produtividade das culturas. De fato, para muitos empreendimentos agricolas, no qual o tempo influencia no resultado final, um modelo numérico produzirá uma interpretação mais racional e objetiva das influências do 
tempo, do que meras considerações subjetivas. Deve-se ter o cuidado no momento de selecionar ou desenvolver um modelo, para assegurar que os resultados a que se propõe forneçam informações que possam ser interpretadas de uma maneira prática, e que os dados de entrada do modelo sejam compativeis com os dados disponiveis ou com a facilidade de se obter dados especiais. A necessidade de computadores, interpretações analíticas e transmissão dos dados devem ser cuidadosamente analisados, uma vez que as informações finais e relatórios devem chegar aos usuários no tempo oportuno (ROBERTSON, 1983)。

o modelo não pode conter todos os atributos do sistema pois, em tal situação, deixaria de ser modelo e seria o próprio sistema real. Com a popularização dos computadores, permitiu-se um avanço muito grande na área de simulação matemática. Pouco vale um modelo sofisticado se as informações necessárias são escassas e de difícil obtenção (PEREIRA, 1987).

ROBERTSON (1983), classifica os modelos mais utilizados, para estimativa de produtividade, como empíricoestatisticos, físico-estatísticos e dinâmicos.

Embora grandes avanços no conhecimento dos processos de troca de massa e energia no desenvolvimento das culturas, tenham induzido a modelos dinâmicos e mecanismos mais sofisticados, para ROBERTSON (1983), os modelos 
tradicionais empirico-estatisticos continuam a ser desenvolvidos, principalmente porque podem ser feitos para operar com um mínimo de dados disponíveis. Sua confiança no entanto, é geralmente compatível com sua forma e com a limitação dos dados nos quais são baseados. Por esta razão eles são normalmente aplicáveis para as condições locais para as quais foram desenvolvidas. Já os modelos dinâmicos, podem ser feitos para simular dia a dia, o material assimilado fotossinteticamente, baseado primeiramente nas trocas de massa e energia, associado a uma quantidade de diferentes processos naturais de crescimento da planta. Alguns modelos podem ser muito complexos e demandam dados biológicos e meteorológicos. Estes, são mais usados para estudos de fisiologia, crescimento e desenvolvimento de culturas. Nos últimos anos uma grande variedade de modelos tem sido desenvolvidos, para diversas finalidades agrometeorológicas, dependendo de sua aplicação para problemas agrícolas especificos.

Uma boa base de dados também é essencial para o sucesso da operação de qualquer modelo, ainda que um dos mais sérios problemas na agrometeorologia é a necessidade de dados adequados. Assim, antes de fazer um bom modelo, segundo ROBERTSON (1983), é necessário fazer uma consideração sobre a disponibilidade de dados. Existem vários tipos de modelos, cada qual enfocando um problema especifico. Modelos de 
regressão empíricos usando simplesmente dados climáticos, são muito utilizados para controle do uso do solo, zoneamento agroclimático e avaliação de impactos climáticos, já os modelos dinâmicos são utilizados para observar continuamente as condições da cultura, com o propósito de prever estas condições.

o conjunto do sistema solo-planta-atmosfera e a teoria dos processos de troca de massa e energia, são a base teórica da construção dos modelos agrometeorológicos. Sérias dificuldades, são naturalmente encontradas nos estudos deste sistema dinâmico e na análise quantitativa das relações entre desenvolvimento, produtividade e condições climáticas. Para SIROTENKO (1983), as razões destas dificuldades são as seguintes:

- A multiplicidade potencial de fatores que influenciam.

- A natureza não-linear da reação das plantas aos fatores ambientais externos.

- A correlação natural entre os fatores individuais externos (temperatura do ar umidade, intensidade da radiação solar temperatura do ar, etc).

- A natureza não-aditiva da influência de cada fator individual. 
- As trocas substanciais da reação natural de cada planta, à influência dos fatores ambientais durante o periodo vegetativo.

- A presença de um número de elementos inerentes à própria cultura (área da superfície fotossintetisante e o grau de desenvolvimento do sistema radicular), os quais determinam a tendência do desenvolvimento dos processos.

Nos últimos anos, uma combinação de fatores tem conduzido ao desenvolvimento de simulação de modelos dos sistemas biológicos. Para SPLINTER (1974), o refinameto das técnicas experimentais e instrumentação, os quais levam a determinação da resposta dos sistemas biológicos no seu ambiente, foi o primeiro passo importante. o desenvolvimento de câmaras de crescimento (casas de vegetação), fitotrons, istrumentação para medir os parâmetros ambientais, sistemas de coletas de dados computadorizados, tem permitido medidas com melhor precisão. Maís importante contudo, foi o desenvolvimento de linguages de computadores e "softwares", os quais permitem a utilização de dados derivados experimentalmente direto do computador.

CURRY et alii (1990) utilizaram os modelos SOYGRO e Ceres-MAIZE para analizar os efeitos das mudanças climáticas no desenvolvimento e crescimento da soja e milho respectivamente, no sudoeste dos E.U.A.. Para avaliar o 
impacto do aumento do $\mathrm{CO}_{2}$ (dióxido de carbono) na atmosfera, foram utilizados dois modelos de circulação Geral da Atmosfera, desenvolvidos pela NASA, que simularam as condições atmosféricas dobrando-se a quantidade de $\mathrm{CO}_{2}$, ou seja, passando dos 330 ppm atuais para 660 ppm. As variações dos parâmetros meteorológicos tais como; temperatura, precipitação e radiação solar foram utilizados como dados de entrada nos modelos SOYGRo e Ceres-MAIZE. Para comparar os resultados simulados pelos modelos, foram utilizados dados climáticos de 1950 a 1980 (30 anos). Uma vez que o efeito do $\mathrm{CO}_{2}$ afeta diretamete os processos de crescimento da planta, a avaliação final do impacto do dobro da concentração de $\mathrm{CO}_{2}$ na atmosfera, pode ser feita considerando-se os efeitos diretos sobre o clima e sobre a planta. o modelo mostrou, nas várias localidades, um aumento médio de $11 \%$ na produção da soja com o dobro de $\mathrm{CO}_{2}$ na Atmosfera (660 ppm), comparada com niveis normais de $\mathrm{CO}_{2}$ (330ppm). Estudos desta natureza demonstram que a simulação pode ser utilizada como importante ferramenta para estimar os impactos das mudanças climáticas sobre a agricultura.

A data de plantio é um dos principais fatores que influênciam na produtividade da soja. Os efeitos de nove diferentes datas de plantio para duas variedades de soja foram analizados por EGLI \& BRUENING (1992), usando o modelo SOYGRO V5.41. Houve uma significante correlação entre as 
produtividades medidas e simuladas. O sOYGRO, geralmente, previu baixas produtividades associadas com o atraso no plantio. Ainda segundo EGLI \& BRUENING (1992), a facilidade de se utilizar modelos desta natureza, é a habilidade que estes modelos oferecem na manipulação dos fatores ambientais que influenciam no desenvolvimeto e produtividade da soja. Após a calibração, e a verificação de que ele pode prever com precisão os parâmetros da culturạ em estudo, o modelo pode ser usado como uma ferramenta para investigar parâmetros como solo, climáticos e da planta, e a resposta da planta em relação a estes parâmetros. Uma das principais vantagens deste tipo de modelo, é a facilidade em manipular os fatores ambientais, como por exemplo, o tipo de solo e clima, dificeis de investigar em experimentos tradicionais.

Para avaliar as condições hídricas do solo no desenvolvimento da soja e melhorar seu uso e eficiência na irrigação desta cultura, PERRY et alli (1990) utilizaram um sistema de modelagem combinando o modelo SOYGRO V.5.4 e um modelo utilizado para controle de irrigação (DRAINMOD). o sistema mostrou boa capacidade de avaliar os efeitos da irrigação no desenvolvimento da cultura. o balanço hídrico simulado pelo sistema apresentou melhor resultado para períodos de chuva moderada a forte do que para períodos secos. Os resultados indicam que o sistema foi capaz de mostrar os efeitos relativos da irrigação no desenvolvimento 
da planta e consequente produtividade, podendo ser usado para avaliar os impactos econômicos da utilização de um sistema de irrigação.

Utilizando o modelo soYGRo para avaliar a adaptação de variedades de soja no sudeste da Europa, BRISSON et alli (1989) mostraram que o modelo simulou satisfatoriamente o desenvolvimento do ciclo da soja, chegando a um erro de cinco dias para o florescimento e de quatro dias para a maturidade fisiológica, na produtividade de grãos o erro ficou em torno de $10 \%$. 
3. HÄTERTAL E MÉTODOS

3.1 haterial utilizado

Neste trabalho, foram utilizados dados de produtividade e observações fenológicas de soja, obtidos do Ensaio Nacional de Ecologia, conduzido pelo Centro Nacional de Pesquisa de Soja (CNPSo-EMBRAPA), localizado no município de Londrina, Região Norte do Estado do Paraná, para os anos de 1976/1977, 1977/1978 e 1978/1979. Londrina está localizada a $23^{\circ} 19^{\prime} \mathrm{S}$ de latitude, $51^{\circ} 09^{\prime} \mathrm{W}$ de longitude e a uma altitude de $566,00 \mathrm{~m}$.

3.1.1 Dados fenológicos e de produtividade

Os dados de produtividade média e observações fenológicas utilizadas neste estudo, foram feitas para variedade de soja DAVIS, pertentencente ao Grupo de Maturação 
VI, da classificação Americana, e representa o grupo de cultivares precoce, segundo terminologia corrente no Estado do Paraná (QUEIROZ, 1988).

Os parâmetros observados foram:

- Data de semeadura;

- Data de florescimento:

- Data da maturidade fisiológica;

- Número de plantas pọ metro quadrado;

- Número de grãos por metro quadrado;

- Peso médio do grão (g);

- Espaçamento entre Iinhas;

- Profundidade de semeadura;

- Produtividade (kg/ha).

As informações fenológicas e de produtividade, foram obtidas de experimentos conduzidos com tres repetições para cada ano agrícola. As semeaduras foram efetuadas no dia 05/11/76, para o primeiro ano, 04/11/77 para o segundo ano e, 06/11/78 no terceiro ano. O espaçamento utilizado entre as linhas foi de $0,40 \mathrm{~m}$.

A data de florescimento (estágio RI) foi observada quando a maioria das plantas apresentou pelo menos uma flor aberta. A data da maturidade fisiológica (estágio R8), foi observada quando aproximadamente $95 \%$ das vagens atingiram a cor da vagem madura. 


\subsubsection{Dados meteorológicos}

Utilizou-se os dados meteorológicos diários da Estação Meteorológica de Londrina (PR), pertencente ao Instituto Nacional de Meteorologia (INMET), e dados das Normais Climatológicas: 1961/1990 (INMET, 1992).

Os parâmetros meteorológicos observados foram:

- Radiação solar (MJ/mª dia):

- Temperatura máxima do ar ( $\left.{ }^{\circ} \mathrm{C}\right)$;

- Temperatura mínima do ar $\left({ }^{\circ} \mathrm{C}\right)$;

- Precipitação (mm).

A radiação solar diária total ( $\left.\mathrm{MJ} / \mathrm{m}^{2} \mathrm{dia}\right)$ foi estimada pela equação de Ångströn (1924) modificada por Prescott, a partir dos dados de insolação ( $\mathrm{n} \cong$ de horas de brilho solar) e nebulosidade (percentagem da cobertura de nuvens) (VIANELLO \& ALVES, 1991):

$$
Q_{g}=Q_{0}[a+b(n / N)]
$$

onde: $Q_{g}$ é radiação solar global diária ao nivel do solo, Qo é radiação solar global diária no topo da atmosfera, "a" e "b" são coeficientes empiricos, obtidos através de regressão linear para uma determinada localidade, os valores destes coeficientes obtidos para Londrina (PR) foram: $a=0,31$ e 
$b=0,49$; " $n$ " é duração do brilho solar observado e "N" duração astronômica do período diurno.

\section{1 .3 Solo}

No Centro Nacional de Pesquisa de Soja, local dos experimentos, o solo é classificado como Latossolo Roxo distrófico, bem drenado, profundo e ocupando um relevo ondulado (QUEIROZ, 1988).

o modelo utiliza os seguintes parâmetros de solo para entrada: albedo, coeficiente de evaporação do solo no estágio 1, coeficiente de drenagem, número da curva de escoamento (classificação americana), espessura das camadas de solo, fator de ponderação de distribuição das raízes e os limites superior (capacidade de campo), inferior (Ponto de murcha permanente), e de saturação de umidade do solo. Estes limites são mostrados na tabela 3 .

Os parâmetros de solo, foram obtidos no centro Nacional de Pesquisa de Soja $(E M B R A P A)^{3}$, em Londrina (PR), e do Manual CERES-Maize (JONES \& KINIRY, 1986).

3 Comunicação pessoal 
Tabela 3 - Parâmetros de entrada de umidade do solo em cada camada (Fonte: CNPSo - EMBRAPA).

\begin{tabular}{cccc}
\hline $\begin{array}{c}\text { PROFUND. } \\
(\mathrm{cm})\end{array}$ & $\begin{array}{c}\mathrm{CC}^{1} \\
\left(\mathrm{~cm}^{3} / \mathrm{cm}^{3}\right)\end{array}$ & $\begin{array}{c}\mathrm{PMP}^{2} \\
\left(\mathrm{~cm}^{3} / \mathrm{cm}^{3}\right)\end{array}$ & $\begin{array}{c}\mathrm{SAT}^{3} \\
\left(\mathrm{~cm}^{3} / \mathrm{cm}^{3}\right)\end{array}$ \\
\hline $00-05$ & 0.350 & 0.250 & 0.520 \\
$05-15$ & 0.350 & 0.250 & 0.520 \\
$15-30$ & 0.370 & 0.260 & 0.528 \\
$30-45$ & 0.370 & 0.260 & 0.528 \\
$45-60$ & 0.350 & 0.250 & 0.520 \\
$60-90$ & 0.350 & 0.250 & 0.520 \\
$90-110$ & 0.350 & 0.250 & 0.520 \\
$110-130$ & 0.350 & 0.250 & 0.520 \\
\hline \hline
\end{tabular}

1 Capacidade de campo

2 Ponto de murcha permanente

3 Saturação 


\subsection{Modelo utilizado}

o modelo de simulação de crescimento e desenvolvimento da soja SOYGRO V5.42 descrito por JONEs et alli (1989), utilizado no presente trabalho, foi desenvolvido por um grupo de pesquisadores da Universidade da florida (EUA), e faz parte de um projeto coordenado pela Universidade do Hawai, onde as estruturas das bases de dados de solo e climáticos são compatíveis com outros modelos, como o CERESMaize e CERES-Wheat, facilitando assim o uso destes dados entre os modelos. O modelo soYGRo foi desenvolvido para simular o crescimento, desenvolvimento e produtividade da soja. Prevê o desenvolvimento fenológico da cultura (duração dos estádios de crescimento vegetativo e reprodutivo), em função dos parâmetros meteorológicos, de solo, e do tipo de cultivar. A fotossíntese, a produção e divisão da biomassa nas folhas, caules, raizes e frutos é estimada diariamente, dependendo dos fatores climáticos, de solo e da cultivar.

Um submodelo dentro do modelo soYGRo, integra o sistema solo-raízes aos efeitos da precipitação, crescimento das raízes e evapotranspiração, calcula o armazenamento de água no solo e a água disponível na zona das raízes, baseado nos processos de escoamento superficial, percolação e redistribuição da água para cada camada de solo. 
As entradas de dados do modelo, incluem sistemas de entradas naturais, variáveis genéticas, dados da cultura e tratos culturais. Os sistemas naturais consistem de dados meteorológicos, solo e latitude local (CURRY et alli, 1990). Os efeitos de pragas, doenças, ervas daninhas, deficiência de nutrientes e toxidades, bem como fenômenos meteorológicos adversos como ventos fortes, granizo e outros, não são considerados pelo modelo.

Esta versão também permite fazer uma análise sensivel, combinando dados de solo, meteorológicos e genéticos da cultivar, o que nos permite fazer um estudo de risco da cultura, simulando em várias condições de solo e clima.

o SOYGRO possui seis fases distintas de crescimento (WILKERSON et alli, 1983):

- Germinação/emergência;

- Crescimento vegetativo;

- Transição para crescimento reprodutivo, diminuição da área foliar e crescimento das raízes ;

- Expansão da vagem, estabelecimento da vagem, diminuição do crescimento vegetativo;

- Enchimento de grãos;

- Rápida senescência foliar. 
3.2.1 Parâmetros de entrada do modelo

- modelo possui tres grupos de arquivos de entrada. o primeiro grupo, contém informações que gerenciam os arquivos de dados experimentais e de dados meteorológicos. o segundo grupo inclui os arquivos com informações sobre os dados genéticos da cultivar, meteorológicos, de solo e informações sobre o manejo da çultura. o terceiro grupo contém os dados observados em campo, para comparação com os resultados simulados.

os parâmetros genéticos da cultivar Davis, utilizada no presente trabalho, foram obtidos do próprio modelo, uma vez que esta variedade de soja já foi calibrada, e está disponível no arquivo de dados genéticos. Este arquivo de dados contém 23 parâmetros genéticos, sendo que 10 desses parâmetros são constantes para qualquer cultivar, os outros 13 devem ser ajustados para cada tipo de cultivar.

Os parâmetros de solo utilizados pelo modelo SOYGRO V5.42, estão descritos abaixo, com um breve comentário sobre cada parâmetro:

- Albedo do solo: Refletividade do solo, varia de 0,10 para solos secos e escuros com alta quantidade de matéria orgânica, a 0,30 para areias claras de deserto. 
- Coeficiente de evaporação do solo - estágio 1: Varia de $6 \mathrm{~mm}$ para areia a $12 \mathrm{~mm}$ para argila.

- Coeficiente de arenagem: Utilizado para estimar a drenagem no perfil do solo.

- Número da curva de escoamento: É utilizada para estimar o escoamento, e varia de acordo com as práticas agrícolas e condições hidráulicas do solọ.

- Fator de ponderação de distribuição das raf́es: É utilizado para estimar o crescimento relativo das raízes nas camadas de solo.

- Espessura das camadas de solo: Neste trabalho foi utilizada uma camada de solo de $1,30 \mathrm{~m}$, subdividida em oito camadas de 5, 10, 15, 15, $15,30,20$ e $20 \mathrm{~cm}$.

- Conteúdo de umidade no solo em cada camada: Para cada camada são necessárias informações de capacidade de campo ( $C C)$, ponto de murcha permanente (PMP), conteúdo de umidade com solo saturado e quantidade inicial de umidade no solo.

Os valores para os parâmetros de solo, encontramse na tabela 4 .

Além dos parâmetros de solo, são necessários dados meteorológicos diários de, temperaturas máxima e 
mínima, precipitação e radiação solar global. o modelo também permite entrar com informações sobre irrigação e aplicação de fertilizantes. os dados de produtividade e fenológicos utilizados neste trabalho, foram obervados sem o uso de irrigação. Com relação à fertilidade do solo, considerou-se não haver deficiência de nutrientes. 
Tabela 4 - Parâmetros de solo utilizados no modelo SOYGRO V 5.42 .

\begin{tabular}{l|l}
\hline \multicolumn{1}{c|}{ PARÂMETROS DO SOLO } & VALOR \\
\hline Albedo & 0,13 \\
Limite superior de evaporação do & $9,00 \mathrm{~mm} /$ dia \\
solo no estágio 1 & \\
Coeficiente de drenagem no perfil & $0,35 \mathrm{~cm} / \mathrm{dia}$ \\
do solo & 85,00 \\
Número da curva de escoamento & 1,$0 ; 0,9 ; 0,8$ \\
Fator de moderação de distribuição & 0,$4 ; 0,2 ; 0,05$ \\
das raizes nas 8 camadas de solo & 0,$02 ; 0,005$ \\
Profundidade do solo, dividido em & $130 \mathrm{~cm}$ \\
8 camadas de 05, 10, 15, 15, 15 & \\
\hline \hline
\end{tabular}

Fonte: CNPSO-EMBRAPA a Manual do CERES-Maize (JONES \& KINIRY, 1986) 


\subsubsection{Parâmetros de saída do modelo}

Outro grupo de arquivos gerados pelo modelo, são os de saída, os quais contém os resultados simulados. o primeiro arquivo fornece informações sobre o manejo da cultura e solo, datas de todos os estádios fenológicos, biomassa acumulada, índice de área foliar, precipitação e evapotranspiração acumuladas, pem como os parâmetros observados e simulados. Um segundo arquivo, contém informações, onde pode ser selecionado o intervalo de saída em dias, sobre o indice de área foliar, peso de vagens, caules, grãos, folhas, cobertura vegetal, raízes, número de grãos e indice de colheita. No terceiro arquivo, onde também pode ser selecionado o intervalo de saída em dias, contém informações meteorológicas e dos componentes do balanço hídrico.

3.3 Sensibilidade do modelo em relação às variáveis de entrada

A sensibilidade do modelo pode ser testada em relação aos parâmetros de entrada, e serve para avaliar a habilidade do modelo em estimar a produtividade. o teste foi feito com relação aos parâmetros de solo e manejo da cultura, 
variando-se cada um dos parâmetros mantendo-se os outros constantes. 


\section{RESULTADOS E DISCUSSÔES}

\subsection{Condições meteorológicas}

Os dados meteorológicos referentes aos tres anos agricolas do experimento, estão ilustrados nas figuras 3 a 12. Observando os dados de precipitação, podemos verificar que para o ano agrícola 1976/77, as precipitações estiveram próximas à normal. Para o ano agrícola 1977/78, as precipitações ficaram acima da normal nos meses de novembro e dezembro de 1977, e abaixo da normal para os meses de janeiro e fevereiro de 1978, sendo que em janeiro as precipitações ficaram em torno de $40 \%$ da média mensal. Em $1978 / 79$ as precipitações foram um pouco acima da média nos meses de novembro e dezembro de 1978, e fevereiro de 1979, porém, o mes de janeiro de 1979 ficou muito abaixo da normal, aproximadamente $31 \%$ da média mensal. Pode-se dizer que as precipitações foram satisfatórias para o ano agrícola 
1976/77, porém para $1977 / 78$ e 1978/79, não houve uma distribuição adequada.

As temperaturas ficaram próximas à normal nos meses de novembro e dezembro de 1976, e janeiro de 1977, e acima da média nos meses de fevereiro e março de 1977. Para o ano agríicola 1977/78, as temperaturas estiveram próximas à média mensal no final de 1977, porém nos tres primeiros meses de 1978, ficaram acima da normal. No ano 1978/79, as temperaturas ficaram próximas à normal.

A radiação solar global manteve-se acima da média para os tres anos agrícolas analisados. No ano 1976/1977, ficou em torno de 10\% acima da média. Para 1977/78, a diferença acima da normal ficou em torno de $19 \%$, e em 1978/79, verificou-se a maior diferença, aproximadamente 25 \% acima da média. 


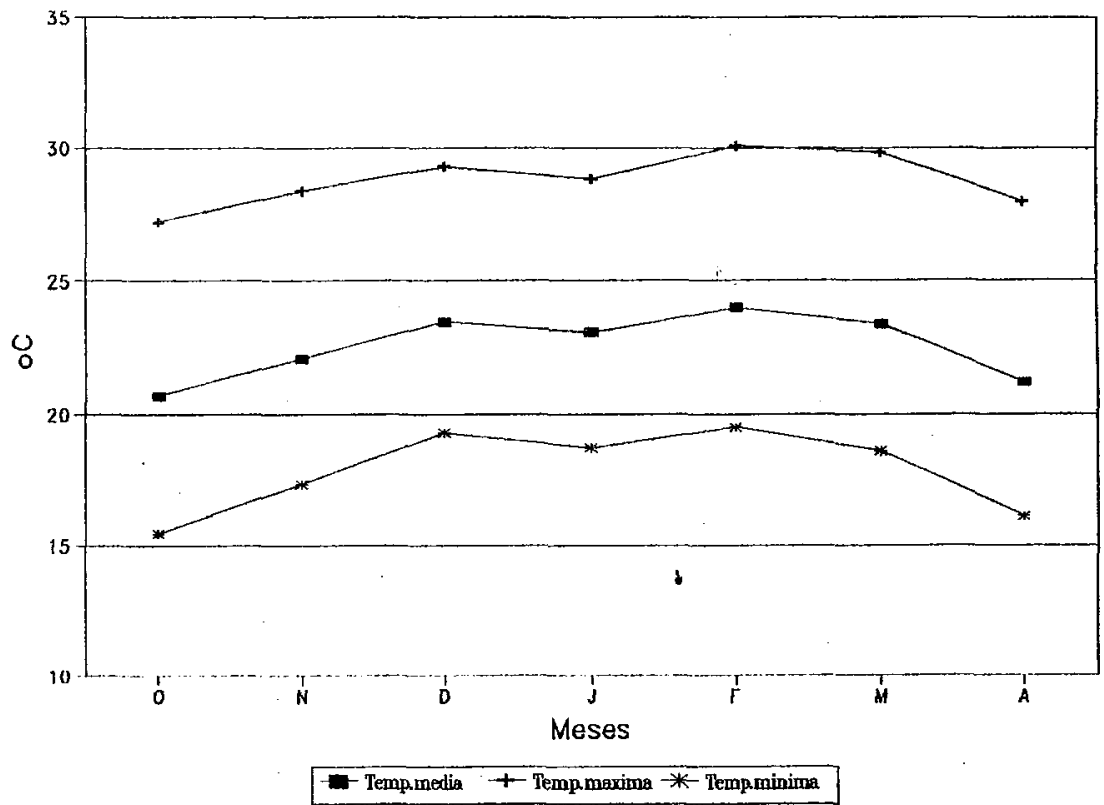

Figura 2 - Temperaturas médias mensais, normais climatológicas $1961 / 1990$ de outubro a abril

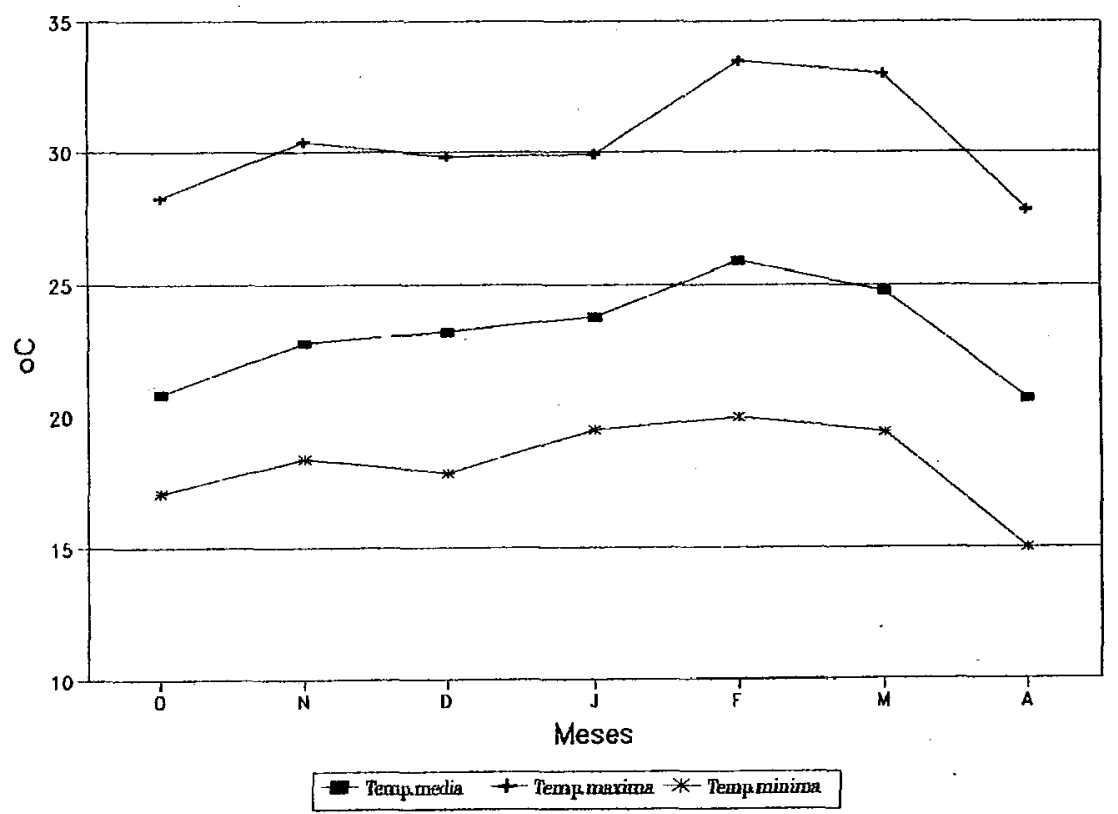

Figura 3 - Temperaturas médias mensais de outubro de 1976 a abril de 1977 


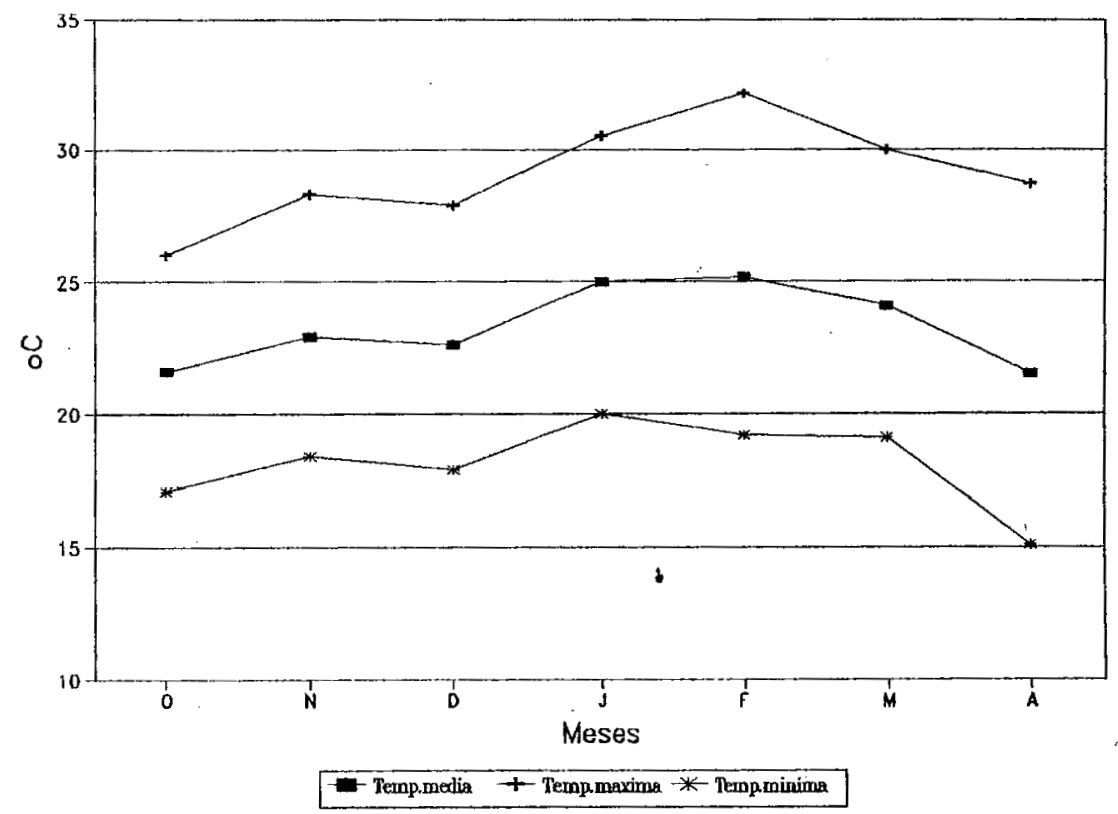

Figura 4 - Temperaturas médias mensais de outubro de 1977 a abril de 1978

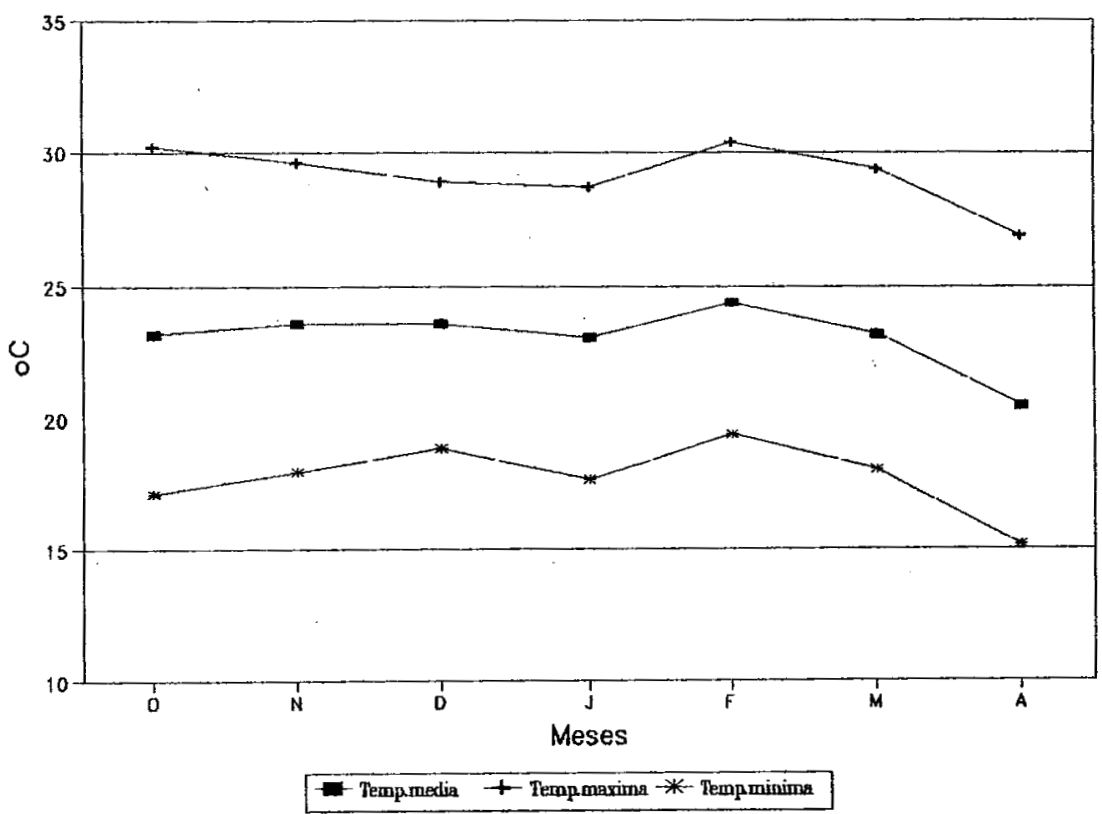

Figura 5 - Temperaturas médias mensais de outubro de 1978 a abril de 1979 


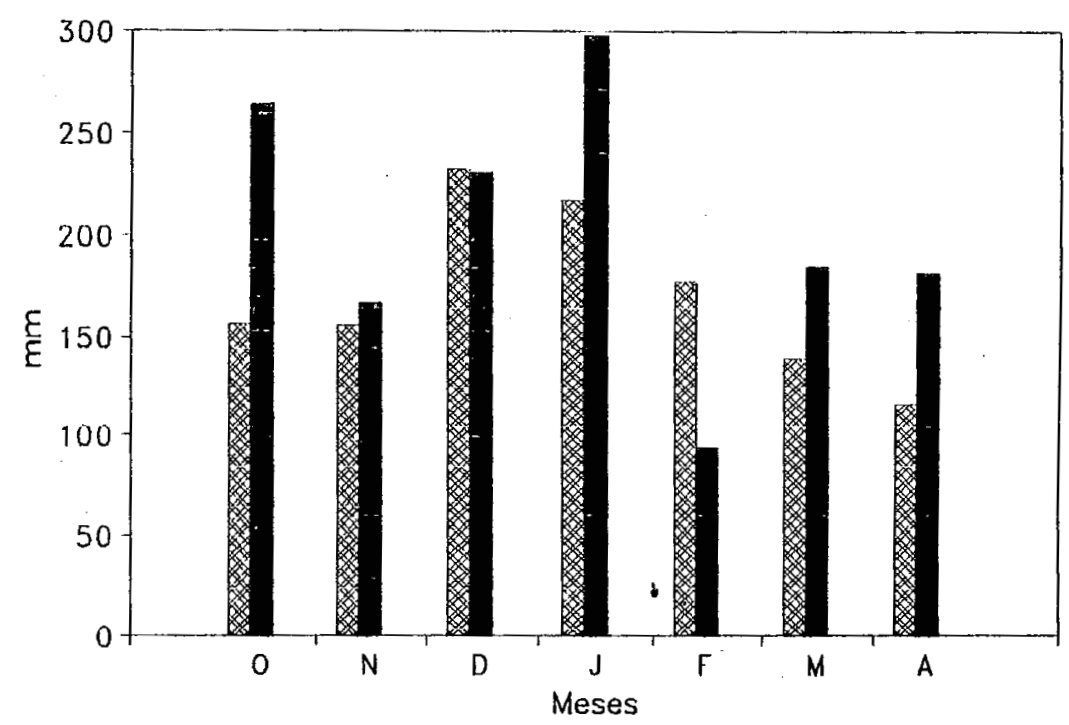

Normais $1961 / 1990$ 1976/1977
Figura $6-\begin{gathered}\text { Precipitação de outubro de } 1976 \text { a } \\ \text { abril de } 1977\end{gathered}$

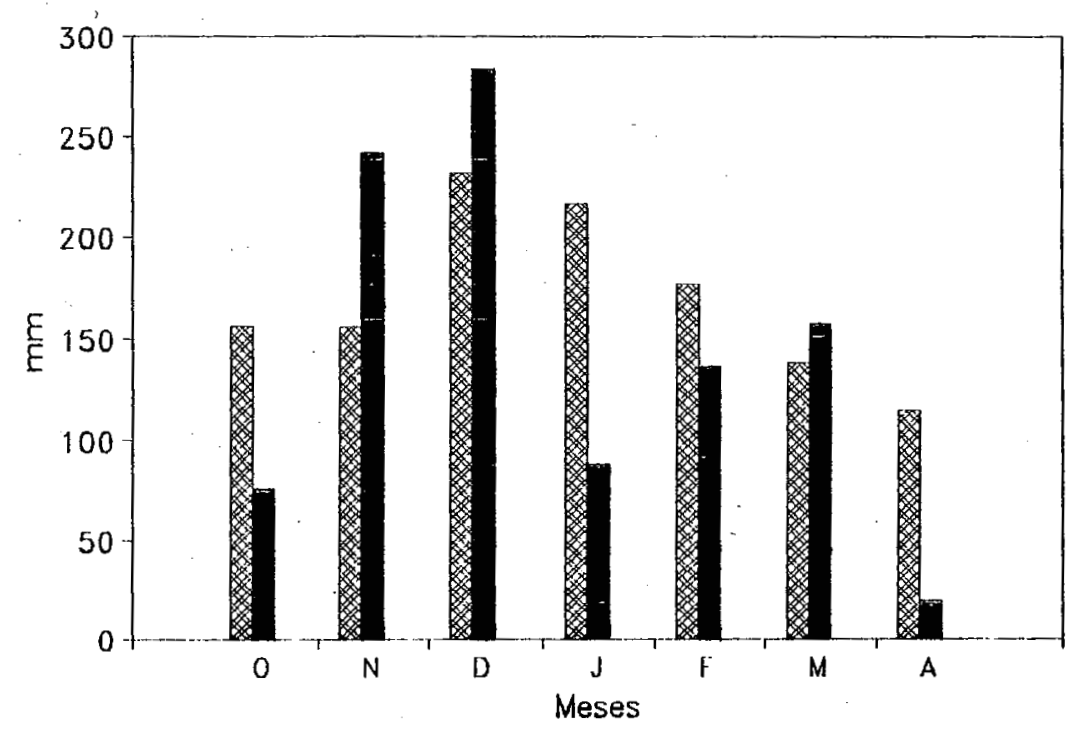

Normais $1961 / 1990 \quad 1977 / 1978$

Figura 7 - Precipitação de outubro de 1977 a abril de 1978 

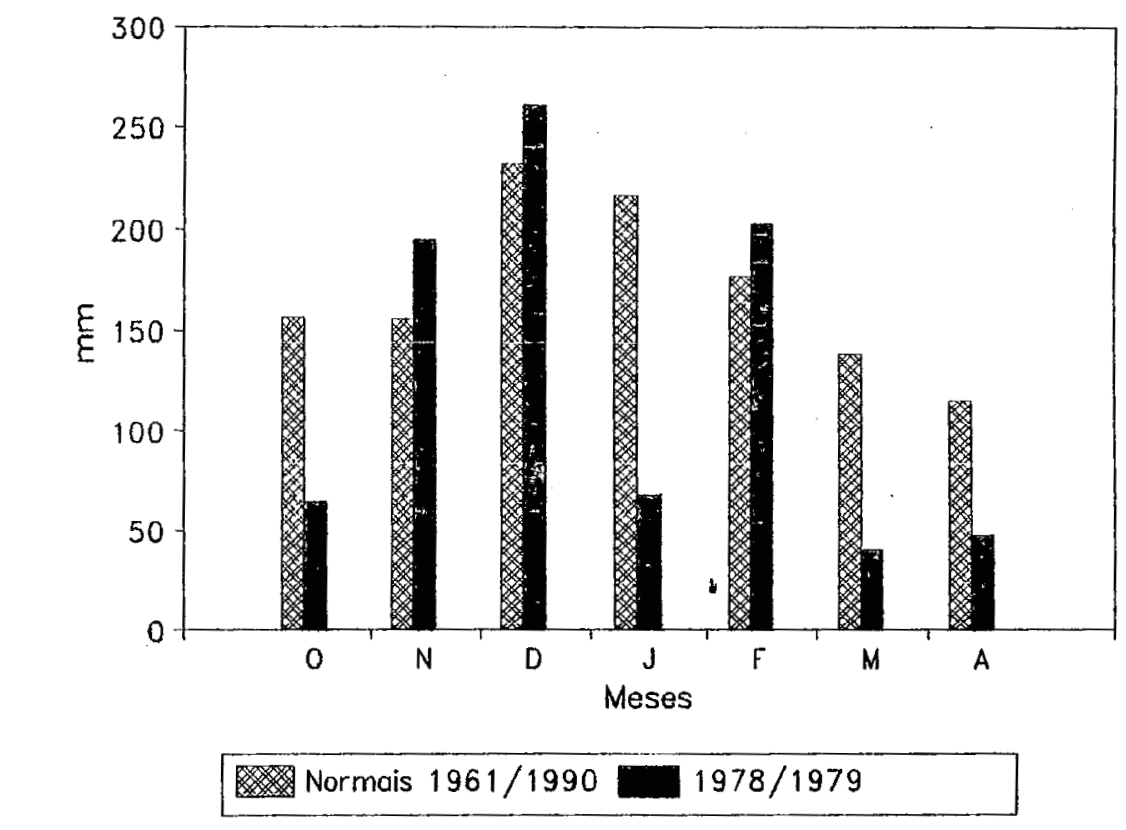

Figura 8 - Precipitação de outubro de 1978 a abril de 1979

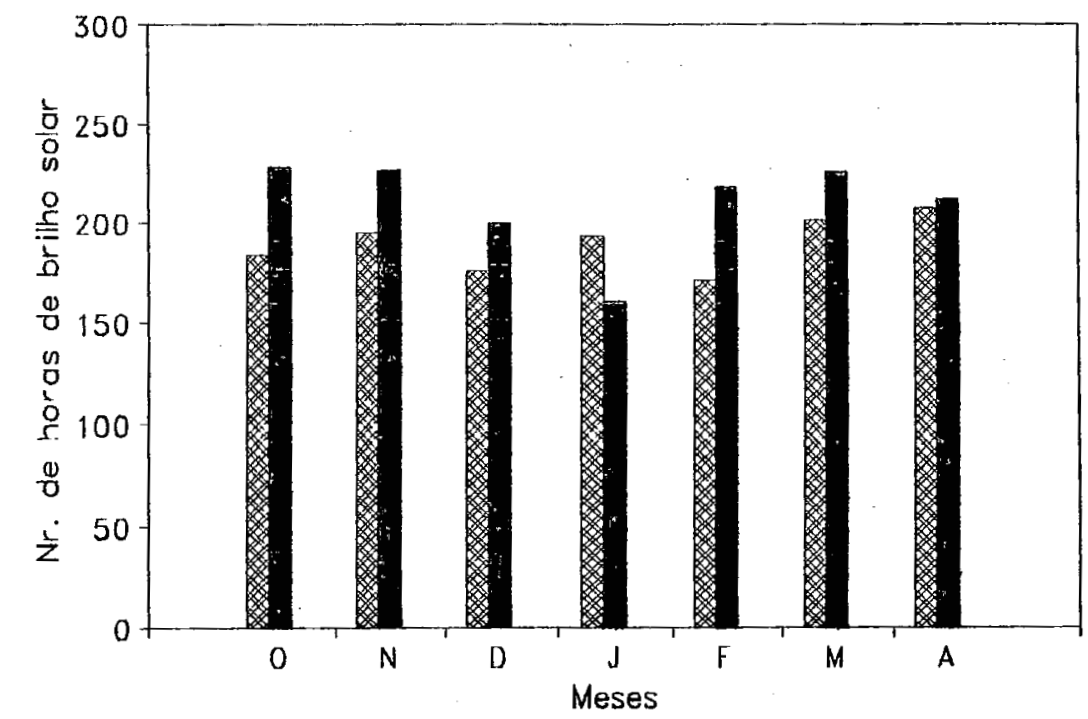

\footnotetext{
Normais $1961 / 1990$

$1976 / 1977$

Figura 9 - Insolação de outubro de 1976 a abril de 1977
} 

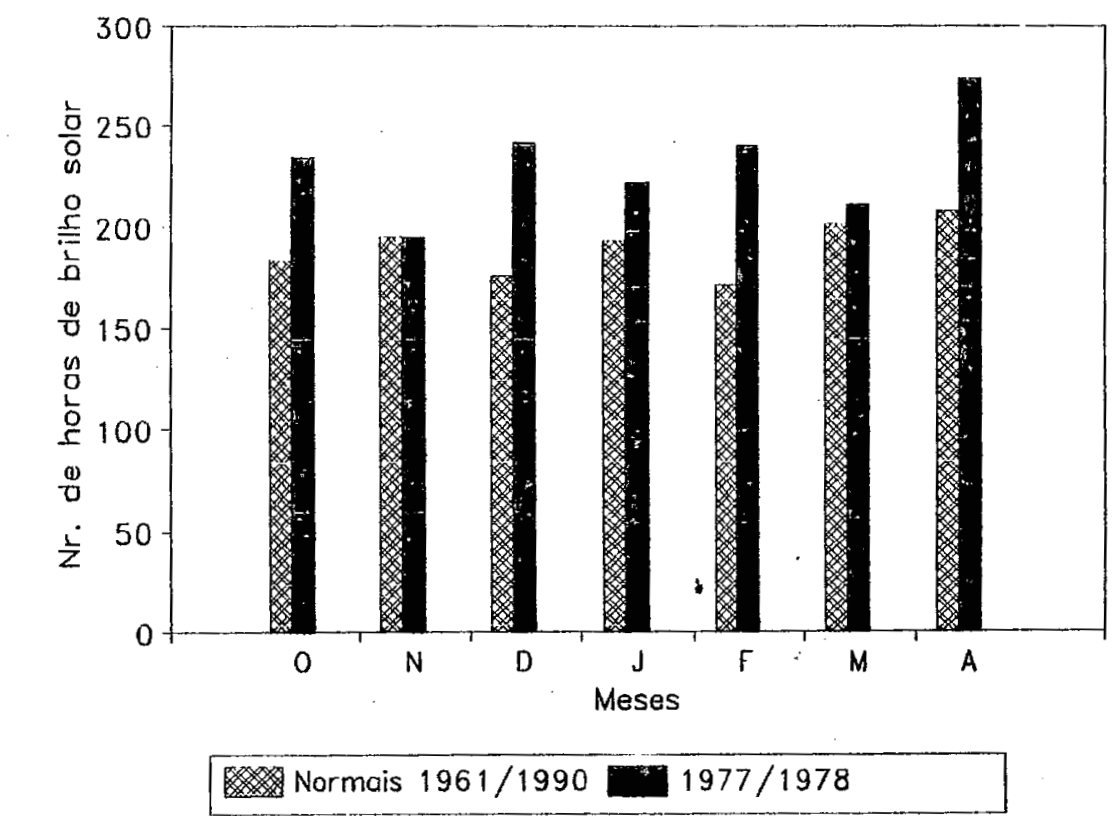

Figura 10 - Insolação de novembro de 1977 a abril de 1978

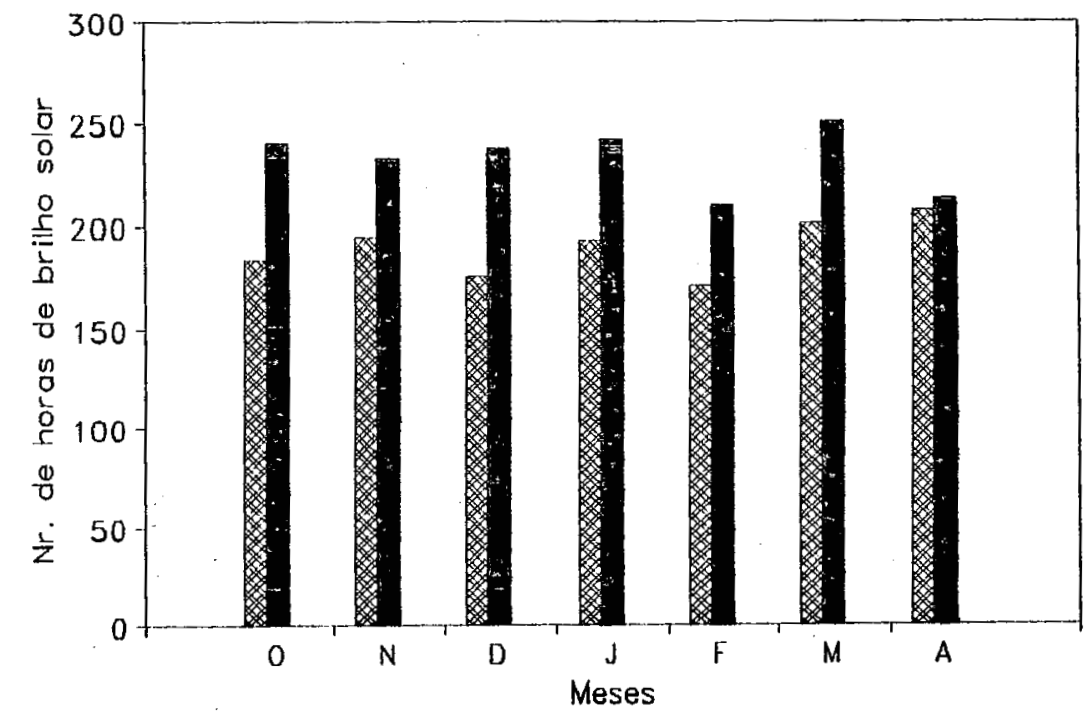

Normais $1961 / 1990=1978 / 1979$

Figura 11 - Insolação de outubro de 1978 a abril de 1979 


\subsection{Estimativa das fases fenológicas e produtjvidade}

o modelo apresenta um arquivo de saida, no qual são apresentadas informações sobre cada fase fenológica da cultura. Este arquivo mostra, para cada fase fenológica, duração de cada fase, biomassa ( $\mathrm{kg} / \mathrm{ha})$, índice de área foliar, evapotranspiração e precipitação acumuladas. Também são apresentadas duas colunas dẹ dados, uma com os dados simulados e outra com os dados observados em campo, dos seguintes parâmetros; data de florescimento, data da primeira vagem, data do término de enchimeto da vagem, data da maturidade fisiológica, produtividade de vagens ( $\mathrm{kg} / \mathrm{ha}$ ), produtividade de sementes ( $\mathrm{kg} / \mathrm{ha})$, percentagem de cascas, massa de cada semente $(g)$, número de sementes por $\mathrm{m}^{2}$, numero de grãos por vagem, índice de área foliar máximo, biomassa ( $\mathrm{kg} / \mathrm{ha}$ ) no estádio $\mathrm{R} 8$, caules ( $\mathrm{kg} / \mathrm{ha}$ ) no estádio R8 e índice de colheita. Estas informações auxiliam na verificação e comparação entre os dados.

Os dados analisados neste trabalho foram: datas de florescimento e maturidade fisiológica, produtividade de sementes $(\mathrm{kg} / \mathrm{ha})$, massa de cada semente $(\mathrm{g})$ e número de sementes por $\mathrm{m}^{2}$.

Para comparação com os dados simulados pelo modelo, foi feita uma média dos dados obervados nas tres repetições, para cada ano agrícola de; produtividade, massa 
da semente e número de sementes por $\mathrm{m}^{2}$. Os valores dos dados para cada repetição, bem como a média destes valores estão nas tabelas 5,6 e 7 .

Podemos verificar que existe uma variabilidade entre os dados de cada repetição, principalmente com relação aos dados de produtividade.

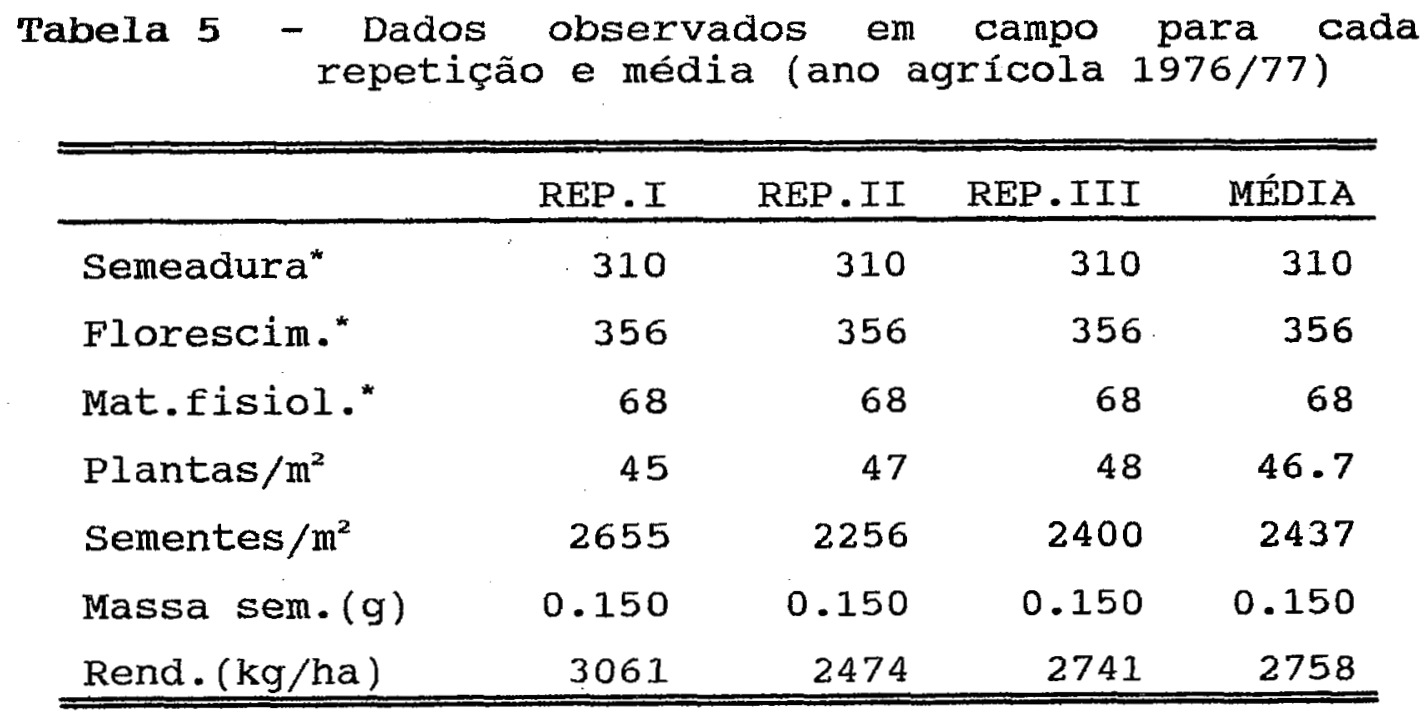

* Dia juliano (1 ${ }^{\circ}$ de janeiro $\left.=01\right)$ 
Tabela 6 - Dados observados em campo para cada
repetição e média (ano agrícola $1977 / 78$ )

\begin{tabular}{lrrrr}
\hline & REP.I & REP.II & REP.III & MÉDIA \\
\hline Semeadura* $^{*}$ & 308 & 308 & 308 & 308 \\
Florescim.* & 352 & .352 & 352 & 352 \\
Mat.fisiol.* & 65 & 65 & 65 & 65 \\
Plantas $/ \mathrm{m}^{2}$ & 46 & 43 & 46 & 45 \\
Sementes $/ \mathrm{m}^{2}$ & 2392 & 1204 & 1702 & 1766 \\
Massa sem.(g) & 0.100 & 0.093 & 0.110 & 0.101 \\
Rend.(kg/ha) & 1588 & 1353 & 1270 & 1404 \\
\hline \hline
\end{tabular}

Tabela 7 - Dados observados em campo para cada repetição e média (ano agrícola 1978/79)

\begin{tabular}{lrrrr}
\hline & REP.I & REP.II & REP.III & MÉDIA \\
\hline Semeadura* & 310 & 310 & 310 & 310 \\
Florescim.* & 356 & 356 & 356 & 356 \\
Mat.fisiol.* & 76 & 76 & 76 & 76 \\
Plantas $/ \mathrm{m}^{2}$ & 42 & 42 & 47 & 43.7 \\
Sementes $/ \mathrm{m}^{2}$ & 1386 & 1134 & 1410 & 1310 \\
Massa sem.(g) & 0.210 & 0.190 & 0.200 & 0.200 \\
Rend. $(\mathrm{kg} / \mathrm{ha})$ & 2261 & 1542 & 2268 & 2024 \\
\hline \hline
\end{tabular}

* Dia juliano ( 1 - de janeiro = 01$)$ 
Analisando-se as datas de florescimento para os tres anos agrícolas, conforme a tabela 8, observamos que as diferenças entre as datas simuladas pelo modelo e as observadas se mativeram em torno de dez dias para os anos 1976/77 e 1978/79, aumentando para treze dias no ano 1977/78. o modelo simulou para os tres anos agrícolas, um atraso na data do florescimento, aumentando a duração do periodo semeadura-florescimento em aproximadamente dez dias.

Quanto à duração do período semeadura-maturidade fisiológica, podemos observar pela tabela 8, que as diferenças entre as datas simuladas e observadas, foram menores. Porém houve uma maior variabilidade nestas diferenças entre os tres anos agrícolas. o modelo também aumentou o periodo semeadura-maturidade fisiológica para os

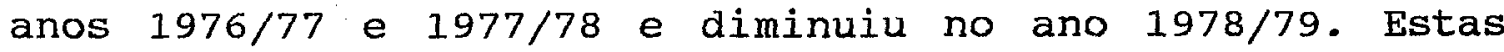
diferenças foram de seis dias para o primeiro ano, dez dias para o segundo ano, e menos um dia para o terceiro ano.

Com relação à produtividade, a tabela 9 mostra que estas foram superestimadas pelo modelo, com excessão do ano 1976/77, onde a produtividade simulada ficou um pouco abaixo da observada, ficando em torno de -3 . Para 1977/78 e 1978/79, as diferenças aumentaram ficando em torno de $+105 \%$ e $+120 \%$, respectivamente.

Pela tabela 10 podemos observar que o modelo também superestimou o número de grãos por $\mathrm{m}^{2}$, nos tres anos 
agricolas, sendo que a menor diferença entre os valores simulado e observado, foi verificada no primeiro ano, sendo de aproximadamente $+8 \%$. As diferenças aumentaram no segundo e terceiro ano ficando em torno de $+39 \%$ e $+99 \%$, respectivamente.

Quanto à massa da semente, a tabela 10 mostra que houve uma variabilidade entre as diferenças dos valores simulados e observados. No primeiro ano, esta diferença ficou em torno de $-33 \%$ para o segundo ano, esta diferença aumentou para $+18 \%$; e, no terceiro ano, diminuiu para $-15 \%$. subestimando a massa da semente para o primeiro e terceiro ano, e superestimando para o segundo ano.

As diferenças observadas entre os parâmetros simulados pelo modelo e observados em campo, podem ter ocorrido, devido a tres fatores:

- A variedade de soja Davis, utilizada para testar o modelo, foi calibrada para condições de solo e clima diferentes das quais foi testada;

- No presente caso, o teste do modelo foi realizado, assumindo-se que não houve deficiência de nutrientes no solo;

- o modelo não considera o efeito de pragas, doenças e ervas daninhas, bem como a 
ocorrência de fenômenos meteorológicos adversos como, ventos fortes, granizo etc.

\begin{tabular}{lrrr} 
Tabela 8 - $\begin{array}{c}\text { Datas de } \\
\text { fisiológica } \\
\text { observadas }\end{array}$ & $\begin{array}{c}\text { florescimento } \\
\text { (dias juliano), }\end{array}$ & $\begin{array}{c}\text { maturidade } \\
\text { simuladas e }\end{array}$ \\
\hline ANO & SIMUL. & OBSERV. & DIFER. \\
$\begin{array}{l}\text { Floresc. } \\
\text { Mat.fisiol. }\end{array}$ & 366 & 356 & +10 \\
& 74 & 68 & +06
\end{tabular}

$1977 / 78$

Floresc. 365

352

$+13$

Mat.fisiol.

75

65

$+10$

$1978 / 79$

Floresc.

001

356

$+10$

Mat.fisiol.

75

$76-01$


Tabela 9 - Rendimento ( $\mathrm{kg} / \mathrm{ha}$ ), observado e simulado

\begin{tabular}{ccccr}
\hline \multirow{2}{*}{ ANO } & \multicolumn{2}{c}{ OBSERVADO } & \multirow{2}{*}{ SIMUL. } & \multirow{2}{*}{ DIFER. } \\
\cline { 2 - 4 } & MÉDIA & D.PAD. & & \\
\hline $1976 / 77$ & 2758 & 294 & 2678 & $-3 \%$ \\
$1977 / 78$ & 1404 & 165 & 2890 & $+105 \%$ \\
$1978 / 79$ & 2024 & 417 & 4469 & $+120 \%$ \\
\hline \hline
\end{tabular}

Tabela 10 - Massa de cada semente e número de sementes por $\mathrm{m}^{2}$, observados e simulados

\begin{tabular}{|c|c|c|c|c|}
\hline \multirow[t]{2}{*}{ ANO } & \multicolumn{2}{|c|}{ OBSERVADO } & \multirow[t]{2}{*}{ SIMUL. } & DIFER. \\
\hline & MÉDIA & D.PAD. & & \\
\hline \multicolumn{5}{|l|}{$1976 / 77$} \\
\hline Massa sem. (g) & 0.150 & 0 & 0.101 & $-33 \%$ \\
\hline Sementes $/ \mathrm{m}^{2}$ & 2437 & 202 & 2643 & $+08 \%$ \\
\hline $1977 / 78$ & & & & \\
\hline Massa sem. (g) & 0.101 & 0.008 & 0.119 & $+18 \%$ \\
\hline Sementes $/ \mathrm{m}^{2}$ & 1755 & 597 & 2432 & $+39 \%$ \\
\hline \multicolumn{5}{|l|}{$1978 / 79$} \\
\hline Massa sem. (g) & 0.200 & 0.01 & 0.171 & $-15 \%$ \\
\hline Sementes $/ m^{2}$ & 1310 & 153 & 2612 & $+99 \%$ \\
\hline
\end{tabular}


4.3 Sensibilidade do modelo com relação às variáveis de entrada

Testou-se a sensibilidade do modelo, em estimar a produtividade com relação aos parâmetros de solo, profundidade de semeadura (cm) e densidade de plantio (plantas $/ \mathrm{m}^{2}$ ). Os testes foram aplicados, com base nos dados observados no ano agrícola 1976/77, onde as produtividades simuladas e observadas apresentaram as menores diferenças.

A figura 13 mostra a variação da produtividade em relação à profundidade de semeadura. Pode-se observar que, a produtividade simulada permanece constante, e independente da profundidade de plantio.

Para a densidade de plantio, conforme mostra a figura 14, observa-se uma pequena variação na produtividade à medida que a densidade de plantio aumenta.

Os parâmetros de solo testados foram; albedo, coeficiente de evaporação do solo no estágio 1, coeficiente de drenagem, número da curva de escoamento, fator de moderação de distribuição das raízes, capacidade de campo (CC) e ponto de murcha permanente (PMP).

Os testes aplicados nos parâmetros de solo, como albedo e coeficiente de evaporação do solo no estágio 1 , praticamente não alteraram a produtividade simulada . Estes parâmetros podem ser observados nas figuras 15 e 16 . 
o número da curva de escoamento varia, segundo o Manual CERES-Maize (JONES \& KINIRY, 1986), entre 62 e 91, dependendo das características do solo e manejo da cultura. Os testes foram aplicados para esta faixa de valores, e praticamente não alteraram a produtividade simulada na faixa que vai de 62 a 80 , conforme mostra a figura 17. De 80 a 91, observa-se uma queda na produtividade simulada de até $12 \%$ - modelo mostrou sệsibilidade em relação ao coeficiente de drenagem, esta variação pode ser observada na figura 18. Esse coeficiente é utilizado para estimar a percolação da água no perfil do solo, e provocou uma queda acentuada na produtividade estimada à medida em que aumentase o valor do coeficiente.

Para avaliar a sensibilidade do modelo em relação ao fator de moderação de distribuição de raízes, foram alterados os valores deste fator para cada camada de solo. Estas alterações estão ilustradas na figura 19. Observa-se que este fator produziu uma pequena flutuação na produtividade simulada, sendo que a maior diferença eṇtre as produtividades simuladas e observada não ultrapassaram $4 \%$. Os limites superior (CC) e inferior (PMP) de umidade do solo, foram testados alterando-se os valores destes limites, acima e abaixo daqueles utilizados no presente trabalho. A alteração destes limites permite modificar a disponibilidade hidrica do solo. o teste foi 
aplicado, alterando-se um dos limites e matendo o outro constante.

Variando o limite superior (CC) abaixo de $10 \%$ daquele utilizado no presente trabalho, a umidade disponível diminuiu consideravelmente, não permitindo ao modelo simular - desenvolvimento da soja, devido ao estrese hidrico provocado pela baixa quantidade de umidade disponivel no solo. A mesma situção ocorreu, variando-se o limite inferior de umidade (PMP) acima de $10 \%$ daquele utilizado no presente trabalho.

o modelo apresentou uma alta sensibilidade à estes limites. Os testes mostraram que um aumento de $50 \%$ e $30 \%$ no limite superior, provocaram um aumento na produtividade simulada em torno de $70 \%$ e $60 \%$ respectivamente, enquanto que, uma redução de $10 \%$ no limite superior, reduziu a produtividade simulada em torno de $32 \%$. Para o Iimite inferior de umidade (PMP), observou-se que uma redução de $30 \%$ neste limite, provocou um aumento na produtividade simulada en torno de $64 \%$, para uma redução de $20 \%$ do mesmo limite inferior, a produtividade simulada aumentou aproximadamente $37 \%$. Aumentando o limite inferior de umidade em $10 \%$, observa-se uma redução na produtividade simulada em torno de $29 \%$. As tabelas 11 e 12 mostram as variações da produtividade simulada em relação à 
variação dos limites superior e inferior de umidade disponível. 


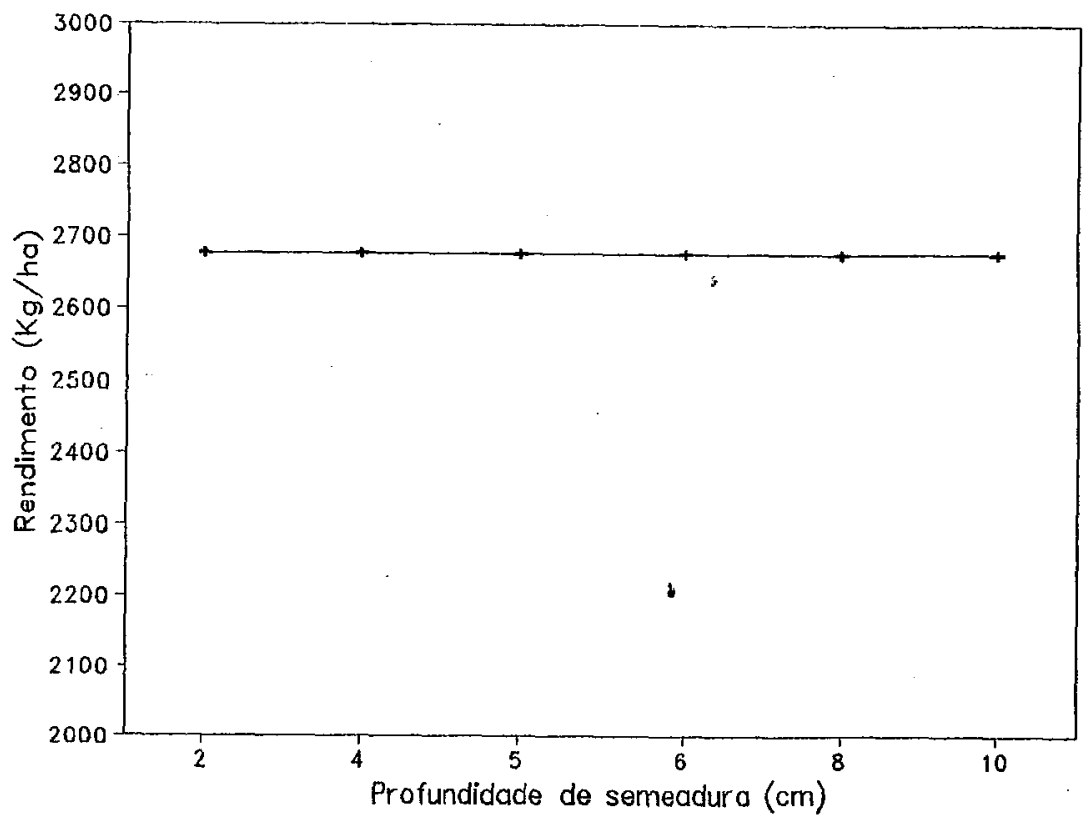

Figura 12 - Variação do rendimento em função da profundidade de plantio

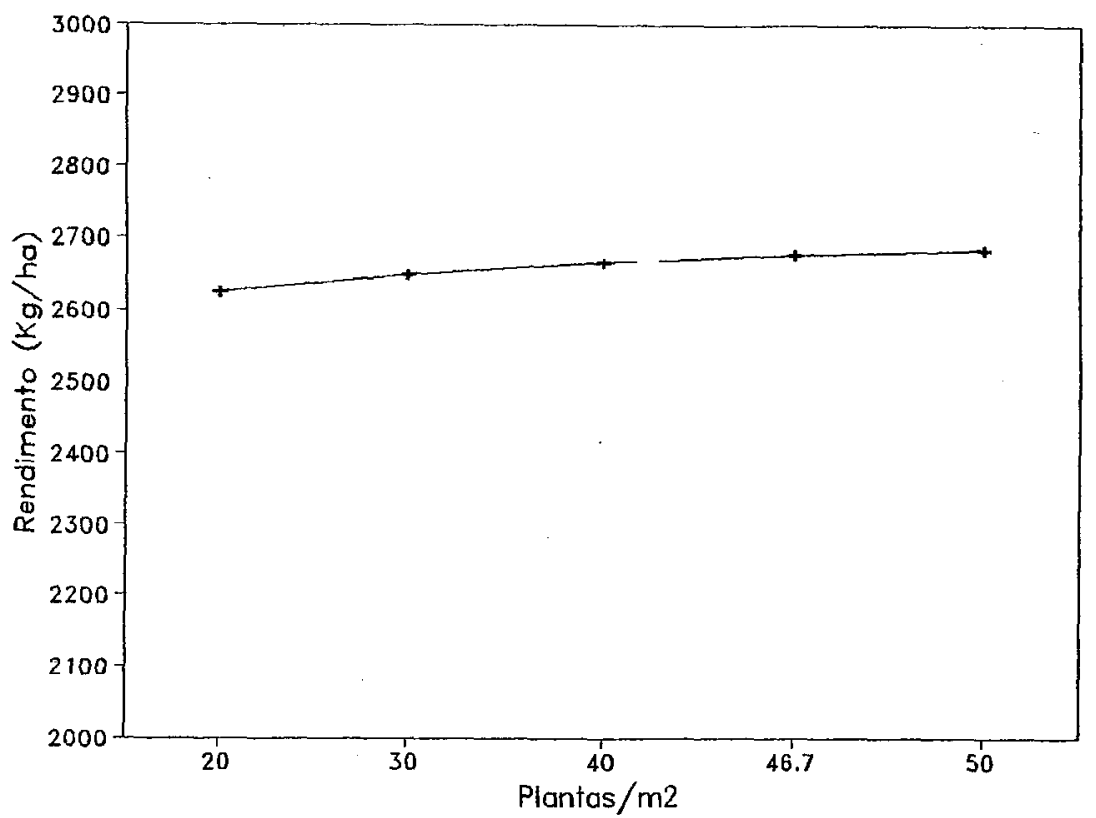

Figura 13 - Variação do rendimento em função da densidade de plantio 


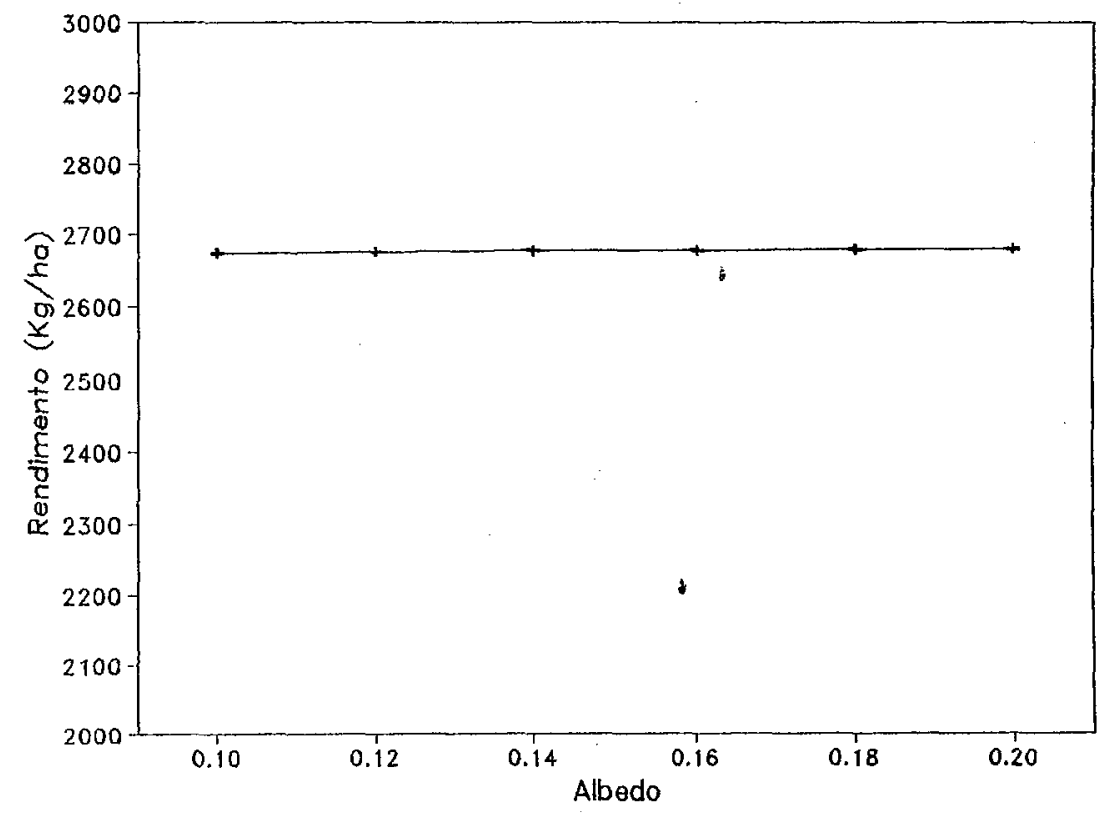

Figura 14 - Variação da produtividade em função do albedo

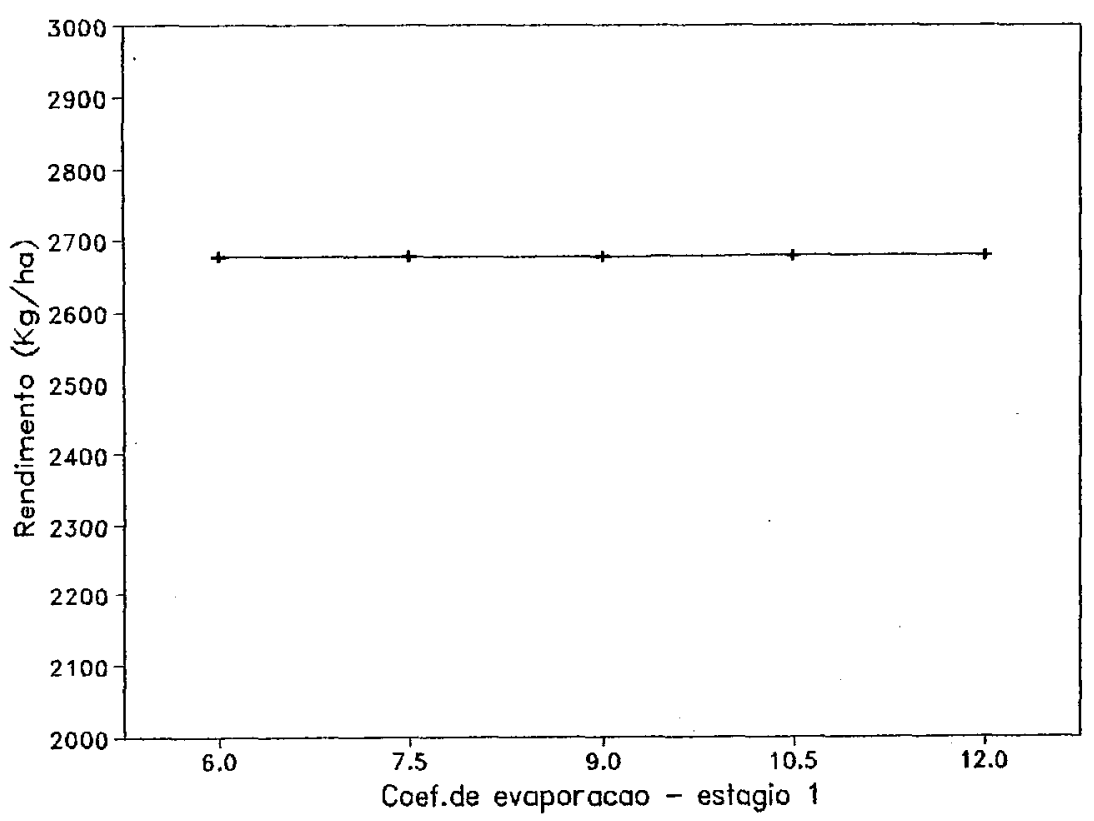

Figura 15 - Variação da produtividade em função do coeficiente de evaporação do solo no estágio 1 


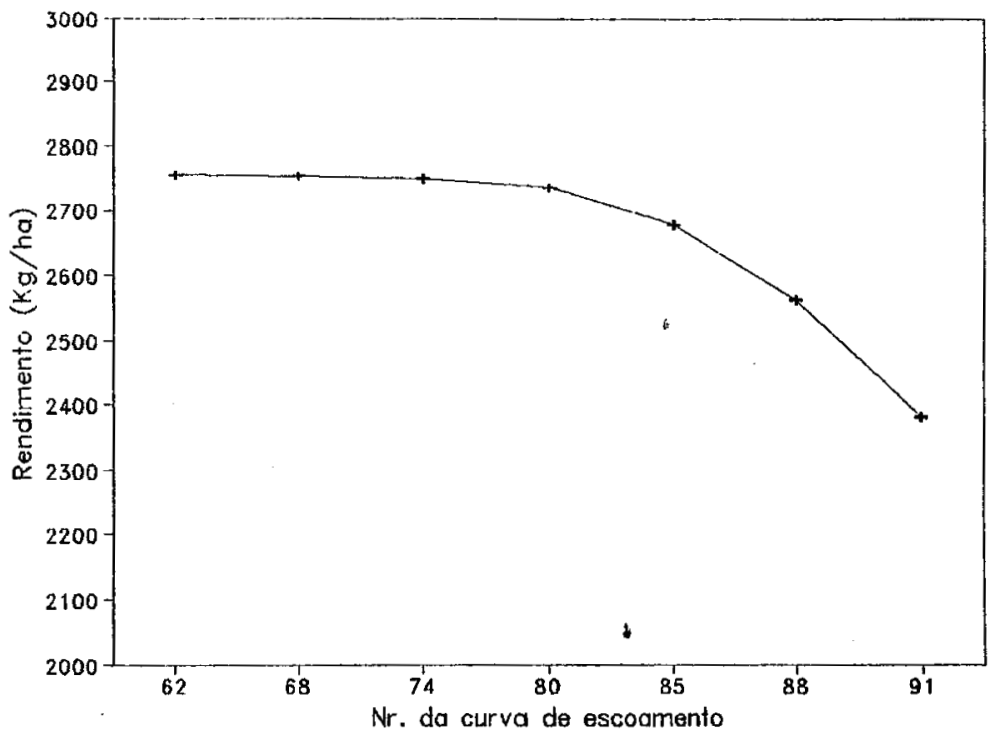

Figura 16 - Variação da produtividade em função do número da curva de escoamento

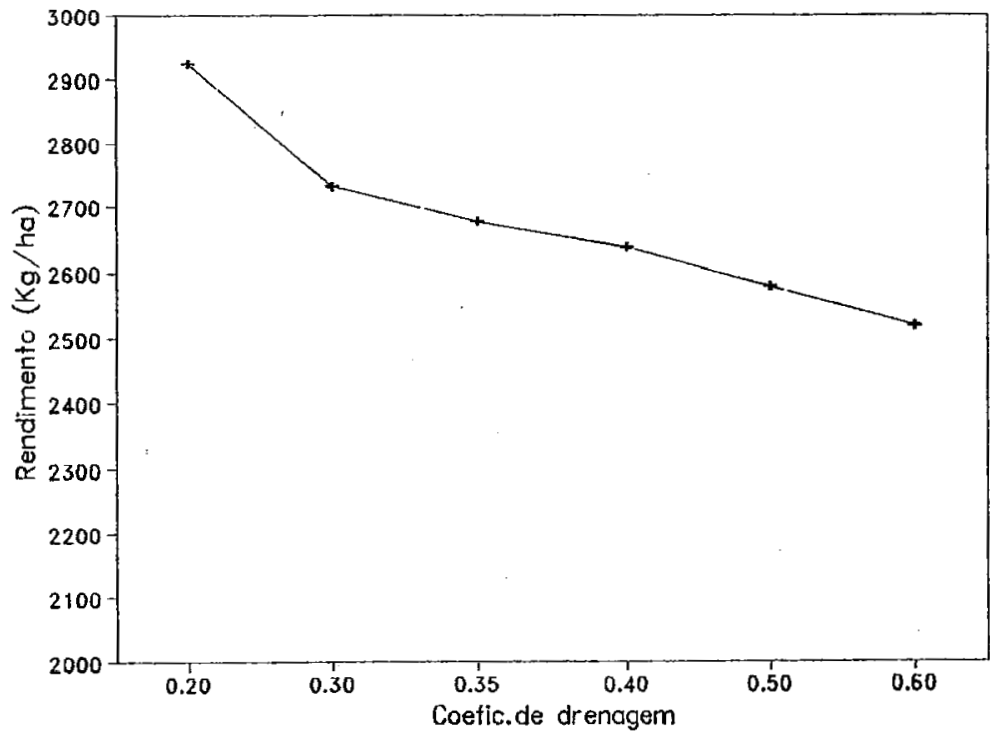

Figura 17 - Variação da produtividade em função do coeficiente de drenagem 


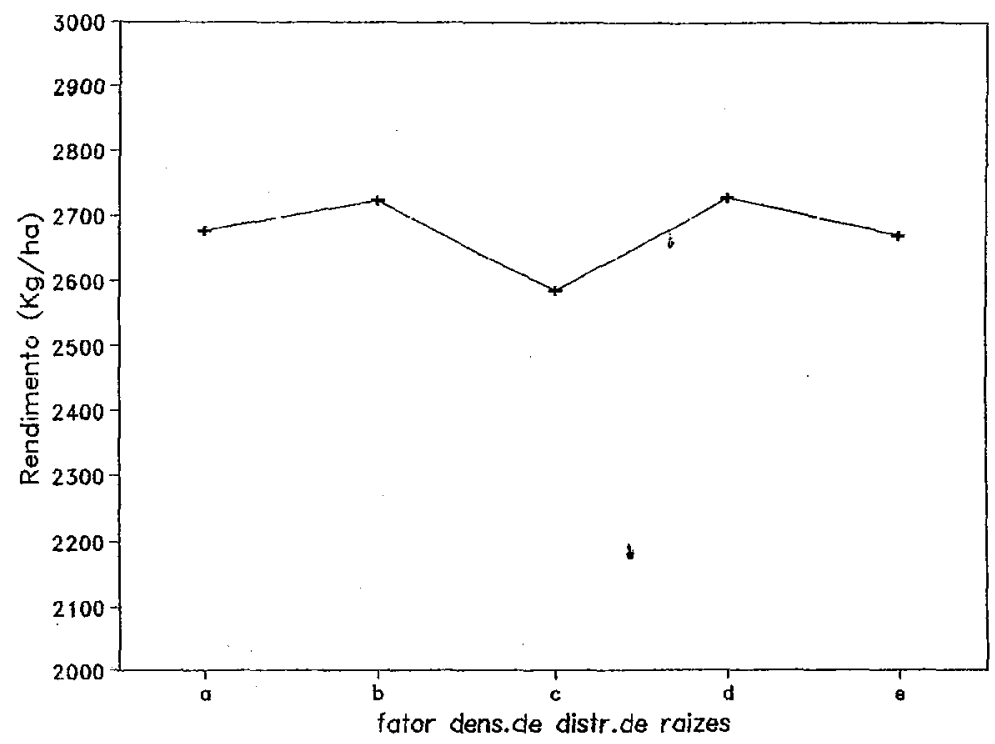

Figura 18 - Variação da produtividade em função do fator de moderação de distribuição de raízes

a) $1.0,0.9,0.8,0.4,0.2,0.05,0.02,0.005$

b) $1.0,0.8,0.6,0.3,0.15,0.05,0.02,0.005$

c) $1.0,0.7,0.5,0.2,0.1,0.02,0.01,0.005$

d) $0.9,0.8,0.6,0.3,0.2,0.05,0.02,0.005$

e) $0.8,0.7,0.5,0.2,0.15,0.04,0.01,0.005$ 


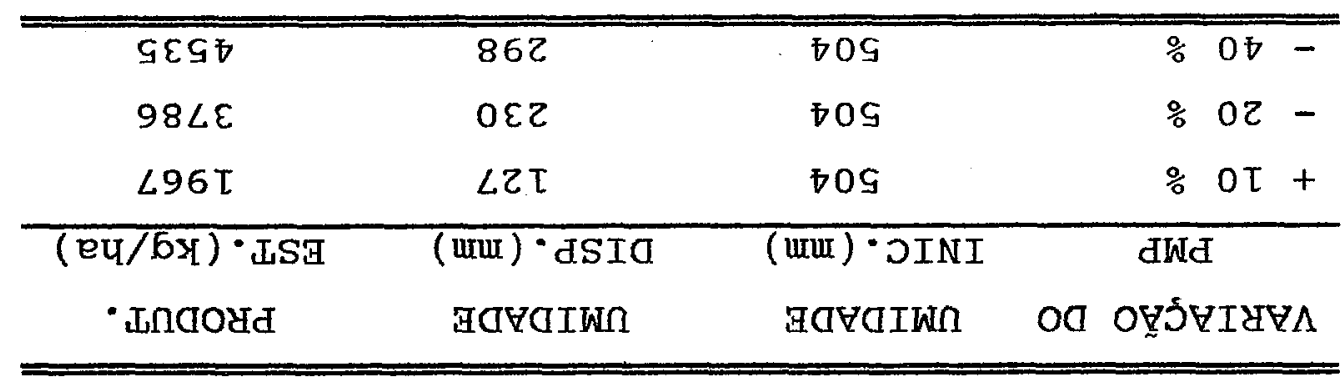

( $\angle L / 9 \angle 6 T$ etostxi6e oue) ә7uezsuos

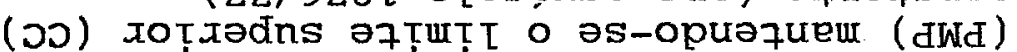

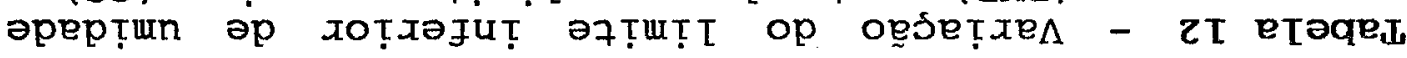

\begin{tabular}{|c|c|c|c|}
\hline $6 \angle 8 T$ & TIT & $\varepsilon G D$ & $\%$ OT - \\
\hline 9260 & $\varepsilon \tau \varepsilon$ & 999 & $\% O E+$ \\
\hline$\nabla S \angle D$ & $\varepsilon \tau \emptyset$ & GSL & $\%$ OS + \\
\hline$($ eu/6Y) & $($ wur $) \cdot$ dSId & $($ uru $) \cdot D I N I$ & 2D \\
\hline - Incozd & BđษवIWn & झดษaIพก & 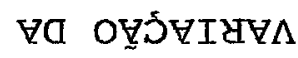 \\
\hline
\end{tabular}

( $\angle L / 9 \angle 6 T$ etootj6e oue) әquezsuos

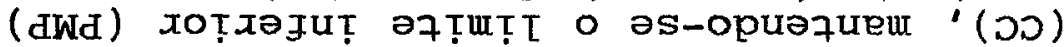

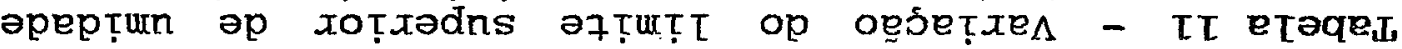

$0 \angle$ 


\section{CONCLUSÕES}

\section{1}

As datas de florescimento simuladas pelo modelo, apresentaram um atraso em relação aos dados observados, aumentando o período semeadura-florescimento em 10 dias aproximadamente para os tres anos agícolas.

As datas de maturidade fisiológica, foram melhor simuldadas pelo modelo, apresentando menores diferenças entre as datas simuladas e observadas. Em geral o modelo apresentou um tendência em aumentar o período semeadura-maturidade fisiológica, com exceção do ano agrícola 1978/79, onde esta diferença foi de um dia.

o modelo mostrou tendência em superestimar a produtividade, com excessão do ano 1976/77, onde a produtividade ficou $-3 \%$ abaixo da observada. As diferenças, entre as produtividades simuladas e observadas, podem ter ocorrido devido aos seguintes fatores: não ter sido considerada a deficiência de nutrientes no presente trabalho, pelo fato da variedade de soja Davis, utilizada para o teste 
do modelo, ter sido calíbrada para condições de solo e clima diferentes das quais foi testada, e o fato do modelo não considerar a incidência de pragas, doença e ervas-daninhas. Profundidade de semeadura e densidade de plantio, utilizados para testar a sensibilidade do modelo em relação à produtividade, mostraram que o modelo é pouco sensivel à densidade de plantio, porém não se mostrou sensivel quanto à profundidade de plantio. o modelo mostrouse sensivel à variação do número da curva de escoamento, do coeficiente de drenagem e do fator de ponderação de distribuição de raízes. Para albedo e coeficiente de evaporação do solo no estágio 1, a produtividade simulada manteve-se praticamente constante.

A maior sensibilidade do modelo, foi observada com relação à variação dos limites superior (capacidade de campo) e inferior (ponto de murcha permanente) de umidade do solo. o modelo superestimou a produtividade quando há mais umidade disponível no perfil do solo, e diminui à medida que há uma redução da disponibilidade hídrica, mostrando que estes limites devem ser bem determinados em campo.

o modelo apresentou resultados satisfatórios, para a estimativa das fases fenológicas. Com relação à produtividade, os resultados mostraram uma variabilidade, porém, os dados observados também apresentaram uma variabilidade entre as repetições. 
Para trabalhos futuros sugere-se:

- Conduzir experimentos em campo, para se obter os dados necessários à calibração dos coeficientes genéticos;

- Realizar observações em campo de todos os dados de entrada necessários ao modelo SOYGRO, e assim testar a precisão do modelo;

- Testar o modelo para outras variedades de soja em outras condições de solo e clima, e verificar a utilização do modelo à estas condições. 


\section{REFERÊNCIAS BIBLIOGRĀFICAS}

BARNI, N.A \& COSTA, J.A. Efeitos de períodos de inundação do solo sobre o crescimento e caracteristicas morfológicas da planta de soja [Glycine max (L) Merrill]. Agronomia Sulriograndense, Porto Alegre, 12(2): 163-172, 1976.

BONETPI, L.P. Considerações sọ̣bre a origem, história e distribuição da soja como espécie cultivada. Trigo e Soja, Porto Alegre, 25: 8-15, 1977.

BONETTI, L.P. Considerações sobre o efeito de períodos de seca no desenvolvimento e produtividade de soja. Trigo e Soja, Porto Alegre, 41: 3-7, 1979.

BRISSON, N.; BONA, S.; BOUNIOLS, A. SOYGRO, un modèle de simulation de la culture du soja; adaptation à des varietés cultivées dans le sud de L'Europe et validation. Agronomie, Versailies. 9, 27-36, 1989.

BROWN, D.M. Soybean Ecology I. Development temperature relationships from controlled environmet studies. Agronomy Journal, Madison, 52 (9): 493-499, 1960 
BROWN, E.A; CAVINESS,C.E.; BROWN, D.A. Response of selected soybean cultivars to soil moisture deficit. Agronomy Journal, Madison, 77: 274-278, 1985.

BROWN, D.M \& CHAPMAN, L.J." soybean ecology II: Development temperature-moisture relashionship from field studies. Agrnomy Journal, Madison, 52 (9): 496-499, 1960.

BRUNINI, O.; MIRANDA, M.A.C.; MASCARENHAS, H.A.A.;PEREIRA, J.C.V.N.A.; SCHIMIDT, N.C. Teste de um modelo agroclimático que relacione o regime pluviométrico com as variações de produtividade agrícola. Brasilia, CFP, 24: 20-46, 1982. (Coleção análise e pesquisa)

CAMARGO, M.B.P. Exigências bioclimáticas e estimativa da produtividade para quatro cultivares de soja no Estado de São Paulo. Piracicaba, 1984, 96 p. (Mestrado - Escola Superior de Agricultura "Luiz de Queiroz"/USP)

COSTA, J.A. Efeito de inundação sobre a soja. Agronomia Sulriograndense, Porto Alegre, 9(1): 113-120, 1973.

CURRY, R.B.; PEART, R.M.; JONES, J.W., BOOTE, K.J.; ALLEN, Jr., I.H. Simulation a tool for analyzing crop response 
to climate change. American Society of Agricultural Engineers, St.Joseph. 33(3):981-990, 1990.

DOORENBOS, J. \& KASSAM, A.H. Efectos del água sobre el rendimiento de los cultivos. Roma, F.A.O, 212 p., 1979. (FAO. Estudio riego e drenage, 33)

EGLI, D.B \& BRUENING, W. Planting date and soybean yield: evaluation of environmental effects with a crop simulation model: SOYGRo. Agricultural and Forest Meteorology, Amsterdam, 62: 19-29, 1992 .

EMPRESA BRASILEIRA DE PESQUISA AGROPECUÁRIA. Centro Nacional de Pesquisa de soja. Recomendações técnicas para a cultura da soja na Região Central do Brasil. EMBRAPACNPSo, Londrina, p. 108, 1992. (EMBRAPA Documentos n: 54).

FINARDI, C.E. \& BERGAMASCHI, H. Comportamento de dezesseis cultivares de soja [Glycine $\max$ (L) Merrill] de diferentes grupos de maturação, em sete épocas de semeaduras, na Depressão Central do Rio Grande do sul. Agronomia Sulriograndense, Porto Alegre, 16(2): 221-245, 1980 . 
GREGAN, P.B \& HARTWIG, E.E. Characterization of flowering response to photoperiod in diverse soybean genotypes. Crop Science, Madison, 24: 659-662, 1984 .

HADLEY, P.; ROBERTS, E.H.; SUMMERFIELD, D.R.; MINCHIN, F.R. Effects of temperature and photoperiod on flowering in soya bean [Glycine $\max$ (L) Merrill]: A Quatitative Model. Annals of Botany Companny, London, 53: 669-681, 1984

INSTITUTO NACIONAL DE METEOROLOGIA. Ministério da Agricultura e Reforma Agrária. Normais climatológicas: 1961/1990. Brasilia, 84 p., 1992.

JONES, C.A. \& KINIRY, J.R. CERES-Maize: a simulation model of maize growth and development. Texas A\&M University Press, College Station Texas, Temple, 194 p., 1986 .

JONES, J.W; BOOTE, K.J; HOOGENBOOM, G.iJAGTAP, S.S; WILKERSON, G.G. SOYGRO V5.42 Soybean crop growth simulation model: User'ś guide. Agricultural Engineering Departament and Agronomy Departament, University of Florida, Gainesville, 75 p., 1989. 
MAJOR, D.J.; JOHNSON, D.R; TANNER, J.W.; ANDERSON, I.C. Effects of daylength and temperature on soybean development. Crop Science, Madison, 15: 174-179, 1975.

MAJOR, D.M. Environmental effects" of flowering. In: FEHR, W.R. \& HADLEY, H.H. Hibridization of crop plants. Americam Soc. Agron./Crop Sc. Soc. of America, Madison, p. $01-15,1980$.

MAYERS, J.D.; LAWN, R.J.; BYTH, D.E. Adaptation of soybean [Glycine max (L) Merrill] to the dry season of the tropics, II. Effects of genotype and environment on biomass and seed yield. Australian Journal Agricultural Research, Melbourne. 42, 517-530, 1991.

oSMAR, S. A cultura da soja 1: Rio Grande do Sul, Santa Catarina, Paraná. Rio de Janeiro, O Globo, 1988. p.299

PASCALE, A.J. \& ESCALES, A. Requerimentos bioclimáticos de los grupos de cultivares de soja I. Subperiodo siembrafloración. Revista de la Faculdad de Agronomia $y$ Veterinaria de Buenos Aires. Buenos Aires, 19(2): 15-24, 1971. 
PASCALE, A.J.; REMUSSI, C.; MARZO, L. Reacción de distintas variedades de soja a los fatores bioclimáticos de Buenos Aires. Revista de Faculdad de Agronomia $y$ Veterinaria de Buenos Aires. Buenos Aires, 15(3): 29-54, 1963.

PEREIRA, A.R. Simulação do crescimento e produtividade. Simpósio Sobre Manejo de Ảgua na Agricultura, Fundação Cargill, Campinas, 17: 201-209, 1987.

PERRY, C.D.: THOMAS, D.I.; SMITH, M.C.; MCCLENDON, R.W. Expert System-based coupling of SOYGRO and DRAINMOD. American Society of Agricultutral Engineers. St. Joseph, $33(3), 991-997,1990$.

QUEIROZ, E.F. Um modelo matemático de quantificação do efeito da oferta hídrica sobre a resposta da soja Glycine $\max ($ L.) Merrill, a época de plantio na Região Norte do Estado do Paraná. Piŕacicaba, 294 p., 1988. (Doutourado Escola Superior de Agricultura "Luiz de Queiroz"/USP)

ROBERTSON, G.W. Guidelines on crop-weather models. World Meteorological Organization, Genebra, WPC-50, 1983. 
ROESSING, A.C. \& GUEDES, L.C.A. Aspectos econômicos da soja: sua participação na econômia brasileira e a evolução na região do Brasil Central. IN: ARANTES,N.E.; SOUZA, P.I.M. Cultura da soja nos cerrados. Piracicaba, Associação Brasileira para Pesquisa da Potassa e do Fosfato, 1993. p. 01-51.

SCHNEIDER, F.M.; SACCOL, A.V.: ,HELDWIEN, A.B.; BURIOL, G.A. O clima. IN: OSMAR, S. A cultura da soja 1: Rio Grande do Sul, Santa Catarina, Paraná. Rio de Janeiro, o GIobo, 1988. p. 39-58.

SEDDIGH, M.; JOLLIFF, G.D. Effects of night teperature on dry matter patitioning and seed growth of indeterminate field-grown soybean. Crop Science, Madison, 24: 704-710, 1984

SEDIYAMA, T.; PEREIRA, M.G.; SEDYIAMA, C.S.; GOMES, J.L.G. A cultura da soja: I Parte. Viçosa, Universidade Federal de Viçosa, , 95 p., 1985.

SEGOVIA, R.M. \& ANDRADE,E.G. Um modelo de determimnação do efeito da precipitação pluviométrica na produtividade agrícola. Brasilia, CFP, $24:$ 10-18, 1982. (Coleção análise e pesquisa) 
SIROTENKO, O.D. Development and application of dynamic simulation models in agrometeorology. World Meteorological Organization (OMM), CAGM, Genebra, 1983. (Report $n^{9}$ 13)

SPLINTER, W.E. Modeliing of plant growth for yield prediction. Agricultural Meteorology, Amsterdam, 14: 243253,1974

THOMAS, J.F. \& RAPPER, Jr., C.D. Photoperiod and temperature regulation of floral initiation and anthesis in soya bean. Annals of Botany Companny, London, 51: 481489,1983 .

THOMAS, J.F. \& RAPPER, Jr., C.D. Photoperiodic control of seed filling for soybeans. Crop Science, Madison, 16: 667$672,1976$.

VERNETTI, F.J. História e importância da soja no Brasil. Agroquímica Ciba-Geigy, São Paulo. 2: 4-10, 1975.

VIANELLO, R.L. \& ALVES, A.R. Meteorologia básica e aplicações. Viçosa, Universidade Fedral de Viçosa, Imprensa Universitária, 449 p., 1992. 